\title{
Re-examining the U.K.'s greatest tornado outbreak: forecasting the limited extent of tornadoes along a cold front
}

Article

Accepted Version

Apsley, M. L., Mulder, K. J. and Schultz, D. M. (2016) Reexamining the U.K.'s greatest tornado outbreak: forecasting the limited extent of tornadoes along a cold front. Weather and Forecasting, 31 (3). pp. 853-875. ISSN 0882-8156 doi: https://doi.org/10.1175/WAF-D-15-0131.1 Available at https://centaur.reading.ac.uk/61279/

It is advisable to refer to the publisher's version if you intend to cite from the work. See Guidance on citing.

To link to this article DOI: http://dx.doi.org/10.1175/WAF-D-15-0131.1

Publisher: American Meteorological Society

All outputs in CentAUR are protected by Intellectual Property Rights law, including copyright law. Copyright and IPR is retained by the creators or other copyright holders. Terms and conditions for use of this material are defined in the End User Agreement.

www.reading.ac.uk/centaur 
Central Archive at the University of Reading

Reading's research outputs online 


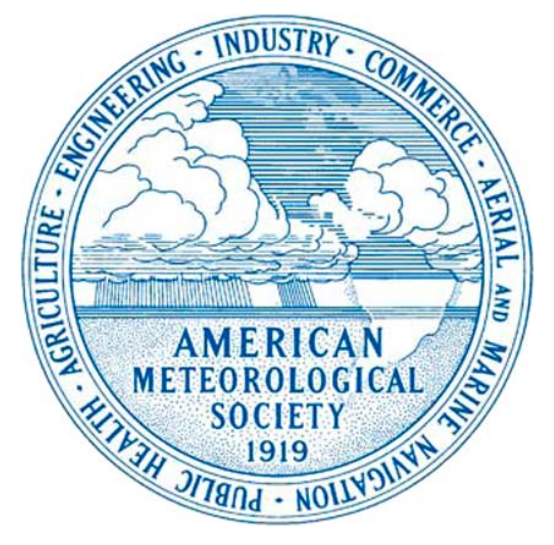

\section{AMERICAN METEOROLOGICAL SOCIETY}

Weather and Forecasting

\section{EARLY ONLINE RELEASE}

This is a preliminary PDF of the author-produced manuscript that has been peer-reviewed and accepted for publication. Since it is being posted so soon after acceptance, it has not yet been copyedited, formatted, or processed by AMS Publications. This preliminary version of the manuscript may be downloaded, distributed, and cited, but please be aware that there will be visual differences and possibly some content differences between this version and the final published version.

The DOI for this manuscript is doi: 10.1175/WAF-D-15-0131.1

The final published version of this manuscript will replace the preliminary version at the above DOI once it is available.

If you would like to cite this EOR in a separate work, please use the following full citation:

Apsley, M., K. Mulder, and D. Schultz, 2016: Re-examining the U.K.'s Greatest Tornado Outbreak: Forecasting the Limited Extent of Tornadoes along a Cold Front. Wea. Forecasting. doi:10.1175/WAF-D-15-0131.1, in press. 


\section{Re-examining the U.K.'s Greatest Tornado Outbreak:}

\section{Forecasting the Limited Extent of Tornadoes}

Along a Cold Front

Centre for Atmospheric Science, School of Earth, Atmospheric and Environmental Sciences, University of Manchester, United Kingdom

Corresponding author address: Prof. David M. Schultz; Centre for Atmospheric Science; School of

Submitted as an Article to Weather and Forecasting 5 October 2015

Revised 12 February 2016 and 28 March 2016

Earth, Atmospheric and Environmental Sciences; University of Manchester; Simon Building, Oxford Road; Manchester M13 9PL, United Kingdom.

E-mail: David.Schultz@manchester.ac.uk 
ABSTRACT

On 23 November 1981, a strong cold front swept across the U.K., producing tornadoes from

46 the west to the east coasts. An extensive campaign to collect tornado reports by the Tornado and

47 Storm Research Organisation (TORRO) resulted in 104 reports, the largest U.K. outbreak. The

48 front was simulated with a convection-permitting numerical model down to 200-m horizontal

49 grid spacing to better understand its evolution and meteorological environment. The event was

50 typical of tornadoes in the U.K., with convective available potential energy (CAPE) less than

$51150 \mathrm{~J} \mathrm{~kg}^{-1}, 0-1-\mathrm{km}$ wind shear of $10-20 \mathrm{~m} \mathrm{~s}^{-1}$, and a narrow cold-frontal rainband forming

52 precipitation cores and gaps. A line of cyclonic absolute vorticity existed along the front, with

53 maxima as large as $0.04 \mathrm{~s}^{-1}$. Some hook-shaped misovortices bore kinematic similarity to

54 supercells. The narrow swath along which the line was tornadic was bounded on the

55 equatorward side by weak vorticity along the line and on the poleward side by zero CAPE,

56 enclosing a region where the environment was otherwise favorable for tornadogenesis. To

57 determine if the 104 tornado reports were plausible, first possible duplicate reports were

58 eliminated, resulting in as few as 58 tornadoes to as many as 90 . Second, the number of possible

59 parent misovortices that may have spawned tornadoes is estimated from model output. The

60 number of plausible tornado reports in the 200-m grid-spacing domain was 22 and as many as

6144 , whereas the model simulation was used to estimate 30 possible parent misovortices within

62 this domain. These results suggest that 90 reports was plausible. 
On 23 November 1981, a strong cold front swept across the U.K., producing an unprecedented 104 reports of tornadoes (Fig. 1). Called "Britain's greatest tornado outbreak"

67 (Rowe and Meaden 1985), this event had many more tornadoes than the next largest event just a 68 month earlier on 20 October 1981, which spawned only 29 tornadoes (Turner et al. 1986; Rowe 69 2016). For comparison, even modest outbreaks by United States standards are relatively 70 uncommon in the U.K. Specifically, over 90\% of U.K. tornado days between 1980 and 2012 had 71 fewer than 8 tornadoes (Fig. 14 in Mulder and Schultz 2015). The November 1981 outbreak is 72 so exceptional that it distorts the historical record and climatologies of tornadoes in the U.K. and 73 Europe. For example, in the U.K. tornado climatology by Mulder and Schultz (2015), several 74 figures had to be plotted with the outbreak excluded (e.g., their Figs. 5-7, 9, 12, 13), and, in their 75 review of tornadoes across Europe, Antonescu et al. (2016) found that the large number of 76 reports produced a bias in their synthesized results and capped the total number of reports from 77 this outbreak at 58. Given the large number of reports distorting the climatologies and that a 78 scientific study of this event has not been performed in nearly 35 years, we believe that the time 79 is right to re-examine this event.

The locations of these 104 reports (Fig. 1) come from the Tornado and Storm Research 81 Organisation (TORRO). TORRO is a U.K. not-for-profit organization responsible for collecting 82 tornado reports from the media, from over 350 observers in the U.K., and from the public 83 through TORRO's website http://www.torro.org.uk (e.g., Elsom et al. 2001; Doe 2016). Of the 84104 reports on 23 November 1981, 35 came from media reports, 30 came from the public after a 85 call for reports on Anglia Television, and 39 were the result of TORRO's appeal in local 86 newspapers (Rowe 1985). The challenges of severe-weather event verification can be immense, 
87 even when events are well observed by expert meteorologists (Speheger et al. 2002; Trapp et al.

88 2006). The challenges are compounded when reports are collected well after the event from

89 primarily nonmeteorologists, as was the case in this event.

90 The first tornadoes of the day occurred in Anglesey, on the west coast of Wales, where there

91 were five reports around 1000 UTC; 20 houses were damaged there, and a summer house

92 (comparable to a small temporary building or mobile home) was turned upside down (Kemp and

93 Morris 1982). The next seven tornado reports occurred near Aughton (near Liverpool) at 1100

94 UTC, and there were four more in Greater Manchester at 1200 UTC. A further 11 reports in the

95 early afternoon came from Birmingham, Nottinghamshire, and the East Midlands (east of

96 Birmingham), where 20 large caravans (camper vans) were blown over (Rowe and Meaden

97 1985). Seven tornado reports clustered near Hull in the early afternoon. Many of the reports

98 (43), however, came from East Anglia (northeast of Cambridge) between 1300 and 1600 UTC.

99 The last tornadoes occurred in southeast Essex (east-northeast of London) just before 1600 UTC.

100 Despite the large number of reports and despite occurring in conjunction with an extensive

101 southwest-northeast-oriented cold front advancing southeastward across nearly the entirety of

102 the U.K., these tornado reports only occurred along a narrow swath 200-250 km wide and 400

$103 \mathrm{~km}$ long (Fig. 1). Thus, the first goal of this article is to determine why the tornadoes occurred in

104 a narrow swath along an otherwise extensive cold front.

105 There are few exact details given with most of the tornado reports, so the duration of each

106 tornado is unknown; some eyewitnesses, however, estimated lifetimes of 20-30 seconds or less

107 (Rowe 1985). Eight tornado reports included damage track lengths between 0.3 and $4 \mathrm{~km}$ long.

108 Where estimated, damage tracks are believed to have had widths of $10-20 \mathrm{~m}$. The direction of

109 travel was reported in 16 cases, with 14 coming from between west and north-northwest, 
110 consistent with the movement of the front; the other 2 came from the south and southwest.

111 Ninety-nine of the 104 reports were assigned values on the International Tornado Intensity Scale

112 or T scale (Meaden 1983; Meaden et al. 2007). Compared to the Fujita (F) scale, the T scale has

113 twice as many classifications. Conversion between the $\mathrm{F}$ and $\mathrm{T}$ scales can be performed using the

114 equation $\mathrm{F} \approx 0.5 \mathrm{~T}$ and rounding down to the nearest integer (Brooks and Doswell 2001; Meaden

115 et al. 2007). Figure 2 shows that most (96, or 97\%) of the tornadoes were T0-T3 (or F0-F1);

116 three tornadoes, however, reached $\mathrm{T} 4$ (or F2). This distribution is similar to the national

117 distribution from the Kirk (2014) and Mulder and Schultz (2015) climatologies in which 94-95\%

118 were between T0-T3 (or F0-F1).

119 Because tornado reporting in this event relied on responses from a media campaign, the

120 figure of 104 tornado reports has been controversial. Extrapolating based on the density of

121 reports and the sparsely populated areas over which most of the cold front traveled, Rowe and

122 Meaden (1985) suggested that the number of tornadoes may possibly have been as high as 400-

123 500. On the other hand, only 58 of these reports (56\% of the 104 reports) were later verified by

124 TORRO experts according to the TORRO database and classified as definite; the other 46 reports

125 were deemed to show reasonable evidence of a tornado having occurred, but not enough to be

126 certain - these were classified as probable. Thus, the lack of confirmation of nearly half of the

127 reports and the extreme magnitude of the outbreak in the historical context suggest that the 104

128 reports might be an overestimate.

129 In this article, we use two different approaches to investigate the tornado reports. First, we

130 undertake a re-examination of the individual tornado reports for the possible occurrence of

131 multiple reports of the same tornado. Second, we use a cloud-resolving model to simulate the

132 cold front and possible parent circulations to the tornadoes. The number of parent circulations 
133 might give us some insight into the number of tornadoes. Thus, the second goal of this article is

134 to re-examine the tornado reports and the meteorological conditions on that day to see if we can

135 constrain the minimum and maximum number of tornadoes that likely occurred.

\section{2. Background on tornadoes along cold fronts}

138 Tornadoes forming along cold fronts are a challenging forecasting problem. Such tornadoes

139 are often associated with a class of convective storms occurring along cold fronts called narrow

140 cold-frontal rainbands. Narrow cold-frontal rainbands have been described by Browning and

141 Harrold (1970), Browning and Pardoe (1973), Carbone (1982), Hobbs and Persson (1982),

142 Browning and Reynolds (1994), Browning and Roberts (1996), Browning et al. (1997),

143 Jorgensen et al. (2003), and Viale et al. (2013), among many others. Narrow cold-frontal

144 rainbands have been synthesized by conceptual models in Browning (1990) and Houze (2014,

145 section 11.4.4). In the United States, narrow cold-frontal rainbands are a subset of what have

146 been termed quasi-linear convective storms (QLCSs; Trapp et al. 2005). Trapp et al. (2005)

147 applied this term for their investigation of tornadoes that form along such line convection (i.e.,

148 distinct from supercell convective storms).

149 Tornadoes along linear convective systems are challenging because they tend to have shorter

150 lead times than tornadoes associated with supercells (Trapp et al. 2005). Even if the specific

151 location and timing of the tornadoes cannot be predicted well in advance, predicting the general

152 location along the line where tornadoes form would be an operationally useful tool. Indeed,

153 Atkins et al. (2004) showed that tornadoes were more likely to form from parent misovortices

154 along the convective line that had greater rotation rates, implying that the strongest vortices may 155 favor tornadogenesis. 
Before discussing how tornadoes form along linear convective storms, we need to distinguish

157 between the parent circulations that precede the tornadoes and the tornadoes themselves. One of 158 the characteristics often observed in narrow cold-frontal rainbands is the presence of 159 precipitation cores and gaps, aligned anticyclonically relative to the front. These core-and-gap 160 regions have been reported for cold fronts over the eastern North Pacific Ocean (e.g., Hobbs and 161 Biswas 1979; Hobbs and Persson 1982; Jorgensen et al. 2003), near the Alps (Hagan 1992), over 162 eastern North America and the Atlantic Ocean (Locatelli et al. 1995; Wakimoto and Bosart 163 2000), and over the U.K. (e.g., James and Browning 1979; Browning and Roberts 1996). 164 Specifically, other tornadic cold fronts in the U.K. also possessed this core-and-gap structure 165 (e.g., Smart and Browning 2009; Clark and Parker 2014; Mulder 2015), as well as in Japan (e.g., 166 Kobayashi et al. 2007; Sugawara and Kobayashi 2009).

167 The cores are often associated with heavier precipitation and relative maxima in vorticity 168 (hereafter misovortices), whereas the gaps are associated with weaker precipitation or the 169 absence of precipitation and relative minima in vorticity. Misovortices have diameters of 1-4 $170 \mathrm{~km}$ (Fujita 1981) and have been suggested to be the parent circulation from which the tornadoes 171 form. Different explanations have been offered to explain misovortex formation, including the 172 release of horizontal shearing instability (e.g., Carbone 1982; Hobbs and Persson 1982; Lee and 173 Wilhelmson 1997b; Jorgensen et al. 2003; Wheatley and Trapp 2008; Kawashima 2011), 174 advection of hydrometeors (Locatelli et al. 1995), trapped gravity waves (Brown et al. 1999), 175 tilting of vorticity along the cold front (Carbone 1983), or combinations of the above.

176 How tornadoes form along linear convective storms is less well known compared to 177 supercellular tornadoes, primarily because detailed field observations of tornadoes forming along 178 linear convective storms have not been collected and because of the large computational expense 
179 of producing a tornado within a numerical model. Because of the shorter lead time and the 180 different parent-storm morphology to supercells, Trapp et al. (1999) suggested that a different

181 tornadogenesis mode may be responsible for tornadoes from linear convective systems than

182 tornadoes from supercells. Carbone (1983) found that the downdraft was coincident with the

183 tornado, suggesting the importance of tilting and a similarity with tornadogenesis in supercells.

184 In contrast, Lee and Wilhelmson (2000) found the importance of stretching of strong initial

185 vorticity in their simulations of nonsupercell tornadogenesis. Nevertheless, the data and

186 simulations in this article will be insufficient to address the issue of tornadogenesis in this case.

187 Thus, we focus on the misocyclones, the locations of the tornadoes, and an approach to forecast

188 the occurrence of tornadoes along lines, as demonstrated for the case of Britain's greatest 189 tornado outbreak on 23 November 1981.

\section{3. Observations: Synoptic and mesoscale overview}

At 12 UTC 22 November 1981, archived Met Office charts identified a broad region of low

193 pressure with two centers of $994 \mathrm{hPa}$ and $996 \mathrm{hPa}$ centered southeast of Iceland and north of the

194 U.K. (Fig. 3a). Twelve hours later, the cyclone consolidated with a central pressure of $986 \mathrm{hPa}$ 195 (not shown). By 12 UTC 23 November, the low had rapidly deepened another $18 \mathrm{hPa}$ to $968 \mathrm{hPa}$ 196 and was moving toward Norway (Fig. 3b), making landfall by 0600 UTC 24 November with a 197 central pressure of $959 \mathrm{hPa}$ (not shown). The cyclone was associated with a sharp trough in 500$198 \mathrm{hPa}$ geopotential height and strong geostrophic cold advection in the lower troposphere, as 199 indicated by the 1000-500-hPa thickness contours (Fig. 4).

200 Associated with this cold advection was a strong cold front at the surface. Archived hourly 201 Met Office surface maps show the front extending to the south of the cyclone across the U.K. 
202 and its southeastward progression (Fig. 5). As the cold front crossed England and Wales, 203 temperatures fell by $6-7^{\circ} \mathrm{C}$ in the first hour, and the pressure rose by as much as $4-5 \mathrm{hPa}$ in the 204 first hour after frontal passage and $3 \mathrm{hPa} \mathrm{hr}^{-1}$ thereafter (Rowe and Meaden 1985; Fig. 5). The 205 wind direction veered suddenly from $190^{\circ}-230^{\circ}$ before the front, a direction roughly parallel to 206 the front, to $320^{\circ}-340^{\circ}$ after the front, a postfrontal direction nearly perpendicular to the 207 orientation of the front (e.g., Fig. 5c). By 1800 UTC, the cold front had cleared England and 208 moved over the North Sea (Rowe 1985; Rowe and Meaden 1985). Moderate rain preceded and 209 was associated with the front in northwestern England at the hour ending 1200 UTC (as much as $21010 \mathrm{~mm}$ per hour; Fig. 6). The infrared satellite image at 1325 UTC (Fig. 7) showed the low 211 center to the north of the U.K. and the broad band of clouds associated with the cold front and a 212 prefrontal band. As the front moved southeastward into central England, the precipitation 213 weakened dramatically to less than $2 \mathrm{~mm}$ per hour during the hour ending at 1400 UTC (Fig. 6).

214 Unfortunately, none of the operational soundings that day were ideal for sampling the 215 prefrontal air. The nearest proximity sounding occurred at Aughton near Liverpool, about $11 \mathrm{~h}$ 216 before frontal passage at 0000 UTC (Fig. 8). This sounding exhibited only $13 \mathrm{~J} \mathrm{~kg}^{-1}$ convective 217 available potential energy (CAPE), a steep lapse rate between 850 and $700 \mathrm{hPa}$, and a strong 60 $218 \mathrm{kt}\left(31 \mathrm{~m} \mathrm{~s}^{-1}\right)$ westerly wind at $850 \mathrm{hPa}$ (Fig. 8). A sounding from the NCEP-NCAR Reanalysis 219 (Kalnay et al. 1996) for a location in western England $\left(52.5^{\circ} \mathrm{N}, 2.5^{\circ} \mathrm{W}\right)$ at $1200 \mathrm{UTC} 23$ 220 November had a surface-based CAPE of $147 \mathrm{~J} \mathrm{~kg}^{-1}$, which is only slightly higher than the 50 $221100 \mathrm{~J} \mathrm{~kg}^{-1}$ of CAPE from the model simulation initialized from the European Centre for 222 Medium-Range Weather Forecasting (ECMWF) reanalyses (jump ahead to Fig. 13).

223 These conditions - strong cold front, small CAPE, prefrontal winds nearly parallel to the 224 front, and postfrontal winds nearly perpendicular to the front-are consistent with weather 
225 conditions associated with other tornado outbreaks in the U.K. (e.g., Bolton et al. 2003; Holden

226 and Wright 2004; Clark 2009, 2013; Clark and Parker 2014; Mulder 2015). Given the synoptic

227 situation, the morphology of the convective storm (also called its convective mode) is likely

228 consistent with previous tornadic convective storms over the U.K., which tend to occur along

229 cold fronts in linear convective storms. Linear convective storms account for $42 \%$ of the

230 tornadoes and $51 \%$ of the tornado outbreaks in the U.K. (Mulder and Schultz 2015), unlike in the

231 United States where linear storms account for only 18-25\% of the tornadoes (Trapp et al. 2005;

232 Smith et al. 2012). [In comparison, supercells produce 79\% of U.S. tornadoes (Trapp et al.

233 2005).] Clark (2013) examined 103 convective lines in the UK and found that 27\% were

234 associated with at least one tornado, further evidence for the importance of these lines in

235 producing tornadoes in the U.K.

236 Because radar data for this event (Doppler winds or even reflectivity) are unavailable, the

237 precipitation structure of the cold front on that day is unknown. Therefore, we investigate this

238 event further with a model simulation.

240 4. Model simulation: Set-up

241 As has been demonstrated for other cases, model simulations can be an effective tool for

242 understanding tornadic fronts in the U.K. (e.g., Smart and Browning 2009; Groenemeijer et al.

243 2011; Mulder 2015). Therefore, we performed a convection-permitting simulation to construct a

244 four-dimensionally consistent dataset to explore a likely meteorological evolution for this event.

245 A successful simulation would be useful to interpret the conditions favorable for the tornadoes

246 within the narrow swath and help interpret the 104 reports of tornadoes. 
The simulation was performed using the Advanced Research Weather and Forecasting 248 Model version 3.4.1 (WRF-ARW; Skamarock et al. 2008). The simulation was initialized at 2490600 UTC 23 November 1981 from the ECMWF reanalysis at $0.25^{\circ} \times 0.25^{\circ}$ grid spacing 250 interpolated onto a Lambert conformal grid. Lateral boundary conditions were provided by the 251 ECMWF reanalyses every $6 \mathrm{~h}$. Otherwise, the simulation was set up exactly the same as that in 252 Mulder (2015) for the more modest U.K. tornado outbreak of 29 November 2011, which featured 253 seven reported tornadoes across Wales and northern England. The simulation featured 90 254 vertical levels and four domains, ranging from the outermost domain with $25-\mathrm{km}$ horizontal grid 255 spacing, to three two-way nested domains of 5-km, 1-km, and 200-m horizontal grid spacing (the 256 innermost two domains are shown in Fig. 9). Even at 200-m grid spacing, the model would have 257 been inadequate to resolve any possible tornadoes. Instead, the innermost domain is analyzed for 258 the existence of misocyclones, small-scale circulations along linear convective systems that may 259 precede tornadoes. Only output from the $1-\mathrm{km}$ and $200-\mathrm{m}$ domains is shown in the present 260 article. Model output was saved for further diagnosis every $30 \mathrm{~min}$ for the 1-km domain and 261 every $10 \mathrm{~s}$ for the $200-\mathrm{m}$ domain.

262 The Kain-Fritsch convective parameterization (Kain and Fritsch 1990; Kain 2004) was 263 employed on the outermost $25-\mathrm{km}$ domain only. Other physical parameterizations included the 264 five-layer thermal diffusion land-surface scheme (Skamarock et al. 2008, their section 8.4.1), 265 Thompson et al. (2008) cloud microphysics, and Mellor-Yamada-Janjić boundary layer (Mellor 266 and Yamada 1982; Janjić 1994, 2002). These parameterizations were chosen because Mulder 267 (2015) found that they produced the most successful simulation of her case. Testing three 268 different microphysical parameterizations (WRF single-moment six-class scheme; Morrison et 
al. 2009; Thompson et al. 2008) did not produce different structures for the core-and-gap regions

270 along the cold front in this case.

\section{5. Model simulation: Mesoscale analysis}

273

The meteorology on the 1-km domain is presented in this section. Subsequent analysis in

274 this article occurs at 1000 UTC, around the time the first tornadoes were reported in Anglesey,

275 and at 1400 UTC, just before the majority of tornadoes were reported in East Anglia. To

276 illustrate the intensity of the front, surface temperature, wind, and sea-level pressure at 1000

277 UTC and 1400 UTC are presented in Fig. 10. The passage of the front was associated with a

278 sharp pressure trough, temperature drop of $6^{\circ}-8^{\circ} \mathrm{C}$, and nearly a $90^{\circ}$ veering of the wind (Fig.

279 10). The winds on either side of the front changed direction from $180^{\circ}-230^{\circ}$ on the warm side to

$280310^{\circ}-330^{\circ}$ on the cold side, although the wind speeds were roughly the same across the front at

281 about $5-10 \mathrm{~m} \mathrm{~s}^{-1}$. The simulation is consistent with the observations reported in section 3 , 282 except for the simulation being an hour behind the observations (cf. Figs. 5a and 10a; cf. Figs. 5c 283 and 10b).

At 1000 UTC 23 November, simulated radar reflectivity factor reveals poorly organized 285 precipitation along the pressure trough over most of the domain, with reflectivities of up to 45 $286 \mathrm{dBZ}$, ahead of the wind shift along the cold front around the time the band first arrived in the 287 U.K. (Fig. 11a). Along the cold front in the northwest part of the domain, a shorter, narrower, 288 more organized, and more intense (45-50 dBZ) line of convection developed (Fig. 11a). As the 289 rainband progressed across the U.K., the areal coverage of the precipitation decreased as the 290 along-front extent of the rainband increased, consistent with the observations (cf. Figs. 6 and 11).

291 In particular, as the line passed over the Pennine mountain range in the center of northern 
292 England, much of the precipitation weakened and the band split into a higher reflectivity line 293 positioned along the front, and a line of precipitation tens of $\mathrm{km}$ ahead of the front (Fig. 11b).

294 The observed counterpart to the modeled prefrontal band, although present in the satellite 295 imagery (Fig. 7 at 1325 UTC), did not appear to produce any measurable precipitation at the rain 296 gauges (Fig. 6 during 1300-1400 UTC). Whether this is because the band was poorly forecast or 297 the stations did not receive rain is unclear at this time. In any case, this prefrontal band is not the 298 focus of the article as it is not associated with the formation of the tornadoes. At maturity of the 299 convective line, cores of stronger precipitation became separated by gaps of about $10 \mathrm{~km}$ in 300 length of lighter or no precipitation, similar to previously published work summarized in section 3012.

The front was associated with a line of absolute vorticity maxima at $500 \mathrm{~m}$ above sea level, 303 which was strongest to the north and weakest to the south (Fig. 12) because the zone of wind 304 shift across the front broadened in association with a weaker pressure trough (Figs. 5b,c and 305 10b). This line of absolute vorticity maxima was between 0.005 and $0.01 \mathrm{~s}^{-1}$ and contained small 306 maxima of $0.01-0.02 \mathrm{~s}^{-1}$, as calculated on the $1-\mathrm{km}$ grid. The line of vorticity moved across 307 Britain with the cold front (Fig. 12); there were maxima in vorticity over Anglesey at 1100 UTC, 308 near Liverpool about 1200 UTC, and in southeast England at 1500-1600 UTC, passing southeast 309 of the U.K. by 1730 UTC. These times correspond within about an hour of reported tornado 310 times (Rowe and Meaden 1985), which is all that can be expected given that the resolution of the 311 tornado reports is only hourly, providing additional faith in the ability of the simulation to 312 reproduce observed features of the front.

313 An examination of the three ingredients for deep moist convection (lift, moisture, and 314 instability; e.g., Johns and Doswell 1992) shows that lift as much as several $\mathrm{m} \mathrm{s}^{-1}$ was present 
315 (not shown), associated with the strong convergence along the cold front inferred from the wind

316 field (Fig. 11b). Moisture and instability can be diagnosed by CAPE (determined from the

317 parcel with the maximum equivalent potential temperature in the column) (Fig. 13). At 1000

318 UTC, CAPE appeared as patchy areas east of the front, but generally less than $50 \mathrm{~J} \mathrm{~kg}^{-1}$ (Fig.

319 13a). By 1400 UTC, CAPE increased ahead of the front, with widespread areas over $25 \mathrm{~J} \mathrm{~kg}^{-1}$

320 and localized maxima approaching $125 \mathrm{~J} \mathrm{~kg}^{-1}$, forming a slightly curved narrow (40-70 km

321 wide) crescent of CAPE ahead of the front (Fig. 13b). (Interestingly, a second maximum of

322 CAPE of $25-125 \mathrm{~J} \mathrm{~kg}^{-1}$ was also present in a $20-50-\mathrm{km}$ wide band about $150 \mathrm{~km}$ ahead of the

323 front associated with the prefrontal rainband, although this maximum is not part of this story.)

324 Therefore, the three ingredients for deep moist convection (i.e., instability, lift, moisture) were

325 present along the front.

326 These large gradients in CAPE occurring over such short distances raise issues about the

327 proximity soundings for U.K. tornadoes. Given the large gradients in CAPE occur over

328 distances as small as tens of $\mathrm{km}$, this raises questions about the choice of proximity sounding

329 criteria used in Mulder and Schultz (2015) of $180 \mathrm{~km}$ and $3 \mathrm{~h}$. Mulder and Schultz (2015)

330 derived their criteria from previous proximity sounding studies in the United States, specifically

331 Brooks (2009). Indeed, the prefrontal sounding for this outbreak in Fig. 8 does not meet these

332 criteria. Other U.K. soundings on that day were even farther away from the tornadoes. Thus, the

333 large variability in CAPE ahead of the front in this case is consistent with the recommendations

334 for proximity sounding criteria for significant tornadoes in the United States of a range of 40-80

$335 \mathrm{~km}$ and no more than $2 \mathrm{~h}$ (Potvin et al. 2010). Potentially noteworthy is the fact that detailed

336 analysis of CAPE and convective inhibition near supercells in the central United States show

337 variations of hundreds of $\mathrm{J} \mathrm{kg}^{-1}$ over distances as small as a few $\mathrm{km}$ (e.g., Markowski et al. 
2002). Therefore, perhaps our results of such strong gradients over tens of km should not be too

339 surprising.

340 Given the reasonable timing and structure of the modeled front compared to the

341 observations, we can interrogate the model output to determine the reasons that the tornado

342 reports occurred within a relatively narrow swath along the front. Given the existence of

343 organized deep moist convection, the potential for tornadogenesis can be explored with plots of

344 lifting condensation level (LCL), 0-1-km wind shear, and 0-1-km storm-relative helicity. These

345 are quantities known for their ability to discriminate tornadic from nontornadic storms in the

346 United States (e.g., Rasmussen and Blanchard 1998; Thompson et al. 2003, 2012; Craven and

347 Brooks 2004) and Europe (e.g., Púčik et al. 2015; Mulder and Schultz 2015).

348 At 1000 UTC, the lowest LCL along the front was between 600 and $1000 \mathrm{~m}$ (Fig. 14a). By

3491400 UTC, the LCL had dropped along a similar crescent-shaped spatial distribution of low LCL

350 (200-600 m) in the south with patches less than $200 \mathrm{~m}$, and significantly higher LCL (greater

351 than $2200 \mathrm{~m}$ ) behind the front and to the north along the front (Fig. 14b). These results are

352 consistent with conditions for tornadoes in the U.K. Specifically, Mulder and Schultz (2015)

353 found that low LCL height was a statistically significant factor in predicting tornado formation in

354 the U.K., with outbreaks having a mean LCL of about $700 \mathrm{~m}$, as opposed to a null set of

355 convective storms with lightning or hail which had an LCL of $900 \mathrm{~m}$. Therefore, we would

356 expect tornadic storms to be found along the line toward the south where the LCL is lower and

357 the CAPE is higher.

358 The vertical shear of the horizontal wind over the surface to $1 \mathrm{~km}$ layer (i.e., $0-1-\mathrm{km}$ wind 359 shear) displayed a sharp change in magnitude across the front (Fig. 15). Just ahead of the front 360 in the swath where the tornadoes formed, the shear was $10-20 \mathrm{~m} \mathrm{~s}^{-1}$, with values over $30 \mathrm{~m} \mathrm{~s}^{-1}$ in 
361 the prefrontal rainband (Fig. 15b). Behind the front, the shear was only around $5-10 \mathrm{~m} \mathrm{~s}^{-1}$.

362 Storm-relative helicity over 0-1 km also showed rather large values ahead of the front (Fig. 16).

363 In the immediate vicinity of the front in the prefrontal environment, $0-1-\mathrm{km}$ storm-relative

364 helicity ranged from zero to several hundred $\mathrm{m}^{2} \mathrm{~s}^{-2}$ (Fig. 16).

365 Thus, despite the cold front extending across nearly the entirety of the U.K. (Figs. 5b,c), the

366 narrow swath of tornado reports occurred in what was apparently a sweet spot for the conditions

367 favoring deep moist convection and tornadogenesis along squall lines. Specifically, the swath of

368 tornado reports in this case was limited on the poleward side by the rapidly increasing LCL

369 heights and decreasing CAPE and limited on the equatorward side by the rapidly decreasing

370 absolute vorticity along the cold front, in a prefrontal environment with adequate low-level wind

371 shear and storm-relative helicity all along the front. Although forecasting tornadoes along linear

372 convective systems remains a challenging forecast problem, this sweet spot may provide insight

373 into providing more specificity for nowcasting tornado development along future linear

374 convective systems in the U.K. or elsewhere.

\section{6. Model simulation: Misovortex structure and evolution}

377 The majority of tornado reports occurred within the model domain with 200-m horizontal 378 grid spacing as the modeled front passed through this domain between 1300 UTC and 1640 UTC

379 (Fig. 12). Analysis of vorticity, reflectivity, and surface winds from this domain exhibits more 380 detail along the front where the majority of tornado reports occurred. This region is also where 381 this apparent sweet spot favorable for tornadogenesis occurred. 
At this higher resolution, more detail in the structure and evolution of the misovortices is

383 apparent. Specifically, regions of larger 500-m absolute vorticity $\left(0.02-0.03 \mathrm{~s}^{-1}\right)$ developed into 384 maxima of $0.035-0.04 \mathrm{~s}^{-1}$ within the line, with $500-\mathrm{m}$ updrafts of $5-10 \mathrm{~m} \mathrm{~s}^{-1}$ (e.g., Fig. 17).

385 Pairing of absolute vorticity maxima and minima was common both within the line and in a few 386 patches a little ahead of the line, where there was some higher reflectivity as well. Some 387 merging and splitting of downdrafts and maxima, which has been shown to increase vorticity 388 (Lee and Wilhelmson 1997a), was observed, as well. Background reflectivity of 35-45 dBZ 389 occurred within the rainband, with some patches of higher reflectivity of 50-55 dBZ. Similar to 390 the core-and-gap structures observed by Mulder (2015), the shapes of the misovortices at their 391 maximum intensity are quite similar to each other, specifically, an updraft (usually 5-10 $\mathrm{m} \mathrm{s}^{-1}$ ) 392 located poleward of the misovortex and a downdraft $\left(3-6 \mathrm{~m} \mathrm{~s}^{-1}\right.$, although some downdrafts were 393 as large as 6-9 $\mathrm{m} \mathrm{s}^{-1}$ ) located equatorward of the misovortex.

394 Where the rainband looked like a hook or breaking wave at its edge, the misovortex was 395 typically located at the rear edge of the rainband in the area of lower reflectivity (10-15 dBZ), 396 and eventually developed a hook shape (Fig. 18). Many misovortices intensified at the center of 397 the rainband and weakened as they moved backwards relative to the rainband, leaving the 398 misovortices on the cold side. Some evolved from a line of vorticity that curled up and split into 399 two hooks often described as a broken-S (McAvoy et al. 2000; Clark 2011), signatures similar to 400 the line-echo wave pattern (Nolen 1959) and the frontal type of misovortices observed modeled 401 in squall lines (Jewett and Wilhelmson 2006). The hook-shaped echo is likely a response to the 402 circulation around the misovortex. The kinematics of misovortices appear similar to that of 403 supercells and may suggest that tornadoes along lines may form similar to that inside a supercell, 
404 as suggested by Weisman and Trapp (2003). Further investigation is required to confirm 405 whether the dynamics are similar.

406 To estimate how important these hook-shaped cells were in the model, all the misovortices 407 with absolute vorticity greater than $0.02 \mathrm{~s}^{-1}$ were plotted every minute between 1350 and 1450 408 over the 200-m domain when the front was in the plotted area of Fig. $12(110 \times 70 \mathrm{~km})$. Previous 409 simulations of vortices in different storm types have produced vortices about this magnitude. For 410 supercells, Adlerman et al. (1999) found vorticity up to $0.054 \mathrm{~s}^{-1}$. For bow echoes, vorticity 411 magnitudes ranged from 0.009 to $0.02 \mathrm{~s}^{-1}$ (Weisman and Trapp 2003; Trapp and Weisman 2003;

412 Wheatley and Trapp 2008; Atkins and St. Laurent 2009). For narrow cold-frontal rainbands, 413 Smart and Browning (2009) found vorticity up to $0.04 \mathrm{~s}^{-1}$. Although the modeled vorticity 414 magnitudes depend on the case, they also depend on model grid spacing with higher-resolution 415 models producing higher vorticity values. We determined that $0.02 \mathrm{~s}^{-1}$ was a good balance 416 between choosing a smaller value with vorticity maxima everywhere and choosing a higher 417 value with relatively few vorticity maxima. If the numbers of vortices and vortices with hooks 418 are calculated every ten minutes during that 60-minute period (seven times), then an average of 41939 (with a standard deviation of 3) misovortices existed, of which $20.4 \%$ (with a standard 420 deviation of $2.6 \%$ ) displayed hooks at any one time. Thus, this evolution is relatively common 421 with the model simulation.

\section{Reassessment of number of reports}

424 We can use the simulation, in conjunction with a re-examination of the reports, to re425 examine this event. First, according to the TORRO database, 58 of these reports (56\% of the 104 426 reports) were later verified by TORRO experts, and classified as definite by them; the other 46 
427 reports were deemed to show reasonable evidence of a tornado having occurred, but not enough

428 to be certain - these were classified as probable. So, the minimum number of credible tornadoes 429 was deemed to be 58 .

430 Second, the remaining 46 probable tornado reports were examined for likely duplicate 431 reports. The following approach was followed. Each of the 46 probable reports was checked to 432 see if it might have duplicated another report. Duplicate reports were defined in this article as 433 those reports occurring close in space and time, generally $5 \mathrm{~km}$ or closer and reported at the same 434 time. Because the reports in the TORRO database are recorded by the hour, in practice this 435 meant tornadoes reported during the same hour. If the duplicate probable report overlapped with 436 a definite report, then the definite report was retained and the probable report was discarded. If 437 a definite tornado report with unknown intensity was combined with a probable tornado report 438 with known intensity, then the intensity was assigned to the single definite report. If the 439 duplicate probable report overlapped with another probable report, then the more trustworthy 440 probable report was retained and the other report was discarded. Those reports that had been 441 checked by TORRO experts or were possessing tornado tracks, direction of travel or high T442 scale value were deemed to be the most trustworthy and retained. This check reduced the 443 number of probable reports by 14 to 32 . These two checks reduced the number of tornadoes on 44423 November 1981 to as few as 58 and as many as 90 tornadoes (Fig. 19).

445 Does the simulation provide support for this many tornadoes? The innermost model domain 446 over a section of southeast England contained a subset of 52 of the 104 reports and included part 447 of the area targeted by Anglia Television with their 30 reports, which is why this area had a 448 relatively high percentage of probable reports (e.g., Fig. 1). The re-examination above reduced 449 these 52 reports to 42 tornadoes (22 definite and 20 probable tornadoes). 
To produce tracks of these misovortices that might be parent circulations for tornadoes, 451 absolute vorticity greater than $0.02 \mathrm{~s}^{-1}$ was plotted every minute over the 200-m domain (Fig. 452 20a). Taking $30 \mathrm{~min}( \pm 2 \mathrm{~min}$ because the data interval is every minute) as an approximate 453 minimum lifetime for a parent misovortex to produce a tornado (e.g., Wakimoto and Wilson 454 1989; Brady and Szoke 1989), the number of misovortices produced by the model was counted. 455 This plot was repeated for absolute vorticity maxima greater than $0.025 \mathrm{~s}^{-1}$, updrafts greater than 4565,6 , and $7 \mathrm{~m} \mathrm{~s}^{-1}$, and downdrafts greater than 2, 3, and $4 \mathrm{~m} \mathrm{~s}^{-1}$ (Fig. 20). The results of counting 457 these tracks are summarized in Table 1, which include the average and median duration of tracks 458 lasting $30 \mathrm{~min}$ or more (termed long-lived), and the longest duration and track lengths. These 459 results show a substantial number of long-lived tracks of various intensities (e.g., 9 misovortices 460 of $0.025 \mathrm{~s}^{-1}$ or more, 23 updrafts of $5 \mathrm{~m} \mathrm{~s}^{-1}$ or more, 10 downdrafts of $2 \mathrm{~m} \mathrm{~s}^{-1}$ or more). Most of 461 the model tracks were from the northwest (note the line of constant longitude in the panels in 462 Fig. 20), consistent with the TORRO reports of tracks being mostly from the northwest. A few 463 tracks from the west or southwest, however, were also present (e.g., Figs. 20a,c), which was also 464 consistent with a few tornado reports.

465 Although some of the tracks of misovortices with vorticity greater than or equal to $0.02 \mathrm{~s}^{-1}$ 466 on the 200-m grid are within $5 \mathrm{~km}$ of each other, tornado reports less than $5 \mathrm{~km}$ apart are more 467 likely to represent the same tornado than ones say $20 \mathrm{~km}$ apart. We can never claim that our 468 approach is perfect, but merely suggests a plausible way to filter possibly duplicate reports. 469 Also, there was some ambiguity in how the locations of the reports were recorded (which may 470 have been as specific as the name of a town, rather than a quantitative latitude-longitude 471 coordinate). Such ambiguities would complicate the assessment of the duplicate reports. 472 Finally, the tornado reports that were discounted were listed as only probable by TORRO, so 
473 there is no risk of eliminating definite tornadoes. Thus, we are confident in the model's ability to

474 produce a large number of misovortices that are consistent with the large number of tornado 475 reports widespread over a large region of England and Wales.

476 If the tornadoes on this day developed from parent misovortices that were formed by the 477 tilting-shear mechanism (e.g., Trapp and Weismann, 2003), we would expect horizontal vorticity 478 to develop first, increase, be tilted vertically by an updraft-downdraft dipole, and then weaken. 479 Thus, we would expect the parent misocyclone to have a shorter lifetime than the updraft. From 480 Fig. 20 and Table 1, examples of tracks of updrafts $\left(5-10 \mathrm{~m} \mathrm{~s}^{-1}\right)$ and tracks of vorticity greater 481 than $0.02 \mathrm{~s}^{-1}$ had similar lengths. The vorticity increased to above $0.025 \mathrm{~s}^{-1}$ along the tracks and 482 then toward the end of the tracks. Downdrafts of 3-6 m s${ }^{-1}$ also appeared alongside these tracks 483 for shorter lengths than the updrafts and of only slightly shorter lengths than the higher vorticity 484 tracks. Counting the number of absolute vorticity maxima of $0.02 \mathrm{~s}^{-1}$ or more that last for $30 \mathrm{~min}$ 485 or longer yields 41 misovortices, with some of the longer-lasting updrafts forming multiple 486 misovortices. Of these 41 misovortices, 30 have updrafts of $5 \mathrm{~m} \mathrm{~s}^{-1}$ or more and downdrafts of 3 $487 \mathrm{~m} \mathrm{~s}^{-1}$ or more each lasting longer than 4 min, meaning that there are roughly 30 possible parent 488 circulations in the 200-m domain alone (Fig. 21). Of these 30 tracks, the average lifetime of the 489 tracks was $47.6 \mathrm{~min}$ (median of $39 \mathrm{~min}$ ), and the longest track was $175 \mathrm{~km}$ and lasted for 109 490 min. When linked with favorable environmental conditions for tornadogenesis in the model and 491 the results of Atkins et al. (2004) who found that tornadoes were more likely to form from parent 492 misovortices along the convective line that had greater rotation rates, the potential existed for the 493 model misovortices to have been tornadic. Thus, these roughly 30 intense misovortices within 494 the innermost domain are sufficient to explain the 22-44 tornado reports within this domain. 
Figure 22 combines the half-hourly absolute vorticity isochrones with the regions with 496 favorable CAPE and vorticity values, and the observed 90 tornado reports. The majority of the 497 tornado reports (89 out of 90) were within the favorable locations (high vorticity along the cold 498 front and nonzero CAPE). Also, there was agreement between the modeled misocyclone tracks 499 and the locations of the tornado reports, providing additional veracity of the simulation. The 500 possibility also existed that these misovortices could have produced multiple tornadoes each. 501 Therefore, these statistics give an indication of the potential of high-resolution modeling to 502 resolve features potentially responsible for the tornadoes, as convection-permitting simulations 503 did 15 years ago for the 3 May 1999 Oklahoma-Kansas supercellular tornado outbreak (e.g., 504 Roebber et al. 2002), and provides justification for a potentially large number of possible parent 505 circulations for tornadogenesis in this event.

\section{8. Conclusions}

The U.K. tornado outbreak of 23 November 1981 is analyzed from a convection-permitting model simulation and a re-examination of the 104 tornado reports collected by TORRO. This 510 case is called "Britain's greatest tornado outbreak" (Rowe and Meaden 1985) because its 104

511 reports were so much greater than the next highest outbreak of 29 . A synoptic situation with a 512 strong cold front, weak CAPE (less than $125 \mathrm{~J} \mathrm{~kg}^{-1}$ ), prefrontal winds nearly parallel to the front, 513 and postfrontal winds nearly perpendicular to the front is consistent with weather conditions 514 associated with other tornado outbreaks in the U.K. (Clark 2009; Clark and Parker 2014).

515 The model simulation produced a narrow cold-frontal rainband along a line of absolute 516 vorticity exceeding $0.02 \mathrm{~s}^{-1}$ on the $200-\mathrm{m}$ grid with embedded maxima of $0.035-0.04 \mathrm{~s}^{-1}$, similar 517 to those in previous simulations of misovortices along cold fronts in the U.K. (Smart and 
518 Browning 2009). Misovortices along the front formed a variety of different structures and 519 evolutions and may have been parent circulations for the tornadoes. A line of reflectivity along 520 the cold front was characterized by precipitation cores and gaps. Updrafts of 5-10 $\mathrm{m} \mathrm{s}^{-1}$ occurred 521 poleward of these maxima of absolute vorticity, and weaker downdrafts of 3-6 m s occurred $^{-1}$ 522 equatorward, suggesting the potential for tilting to be involved in tornadogenesis.

The line of absolute vorticity weakened rapidly to the south in conjunction with a 524 weakened pressure trough. Nearly all of tornadoes reported occurred within a sweet spot where 525 the absolute vorticity was strong enough (more than $0.002 \mathrm{~s}^{-1}$ on the $1-\mathrm{km}$ grid) and the CAPE 526 was positive in an environment that was otherwise favorable for tornadoes $(0-1-\mathrm{km}$ storm527 relative helicity and $0-1-\mathrm{km}$ shear). This approach suggests a means by which regions favorable 528 for tornadoes along squall lines could be forecast in the U.K. and elsewhere. The narrow (tens of $529 \mathrm{~km}$ ) region of positive CAPE in advance of the front also raises concerns about large distances 530 used in determining proximity soundings in previous studies $(100-200 \mathrm{~km})$.

531 Within the model domain with 200-m horizontal grid spacing, 30 possible parent 532 misovortices were present with the following characteristics: absolute vorticity greater than 0.02 $533 \mathrm{~s}^{-1}$, updrafts between 5 and $10 \mathrm{~m} \mathrm{~s}^{-1}$ for longer than $30 \mathrm{~min}$, and downdrafts between 3 and $6 \mathrm{~m}$ $534 \mathrm{~s}^{-1}$ were present for at least $4 \mathrm{~min}$. This number of parent misovortices was comparable to the 535 figure of 22-44 tornado reports in this area. We conclude that the number of reports in this area 536 was potentially credible.

Reassessing the quality, timing and location of the reports allows us to place revised 538 boundaries on the lower and upper limit of the number of tornadoes that day. A final figure was 539 produced of 90 tornadoes: 58 definite and 32 probable, a slight reduction from the 104 total 540 reports. This revision does not eliminate the problem of the event distorting the historical record 
541 (Mulder and Schultz 2015; Antonescu et al., 2016). Even if the lower limit were closer to 58

542 reports, this event would still be the largest documented tornado outbreak in the U.K.

544 Acknowledgements: We thank TORRO, in particular Terence Meaden and Paul Brown, for 545 providing the tornado data for 23 November 1981, and Jeff Trapp, David Smart, and an 546 anonymous reviewer for their comments that have improved this article. We thank ARCHER,

547 the U.K. National Supercomputing Service, for hosting the simulations. The historical weather 548 maps were provided by Mark Beswick of the National Meteorological Archive and Duncan Ball 549 of the Met Office Library, and we thank Stephen Burt for telling us about the existence of these 550 map archives. The satellite imagery was provided by Andrew Brooks and Neil Lonie of the 551 Dundee Satellite Receiving Station. Jonathan Fairman provided the CAPE value from the 552 NCEP-NCAR Reanalysis. Funding for Apsley was provided by the U.K. Natural Environment 553 Research Council through the Manchester-Liverpool Doctoral Training Programme Grant 554 NE/L002469/1. Funding for Mulder was provided by a scholarship from the Faculty of 555 Engineering and Physical Sciences, University of Manchester. Partial funding for Schultz was 556 provided by the Natural Environment Research Council to the University of Manchester through 557 Grants NE/H008225/1, NE/I005234/1, and NE/N003918/1 and by the Risk Prediction Initiative 558 of the Bermuda Institute of Ocean Sciences through Grant RPI2.0-2016-SCHULTZ.

REFERENCES

561 Adlerman, E. J., K. K. Droegemeier, and R. Davies-Jones, 1999: A numerical simulation of 562 cyclic mesocyclogenesis. J. Atmos. Sci., 56, 2045-2069. 
563 Antonescu, B., D. M. Schultz, F. Lomas, and T. Kühne, 2016: Tornadoes in Europe: Synthesis of 564 the observational datasets. Mon. Wea. Rev., doi: 10.1175/MWR-D-15-0298.1.

565 Atkins, N. T., and M. St. Laurent, 2009: Bow echo mesovortices. Part I: Processes that influence 566 their damaging potential. Mon. Wea. Rev., 137, 1497-1513.

567 Atkins, N. T., J. M. Arnott, R. W. Przybylinski, R. A. Wolf, and B. D. Ketcham, 2004: Vortex 568 structure and evolution within bow echoes. Part I: Single-Doppler and damage analysis of the 56929 June 1998 derecho. Mon. Wea. Rev., 132, 2224-2242, doi: 10.1175/1520$570 \quad \underline{0493(2004) 132<2224: V S A E W B>2.0 . C O ; 2}$

571 Bolton, N., D. M. Elsom, and G. T. Meaden, 2003: Forecasting tornadoes in the United 572 Kingdom. Atmos. Res., 67-68, 53-72, doi:10.1016/S0169-8095(03)00083-8.

573 Brady, R. H., and E. J. Szoke, 1989: A case study of non-mesocyclone tornado development in 574 northeast Colorado: Similarities to waterspout formation. Mon. Wea. Rev., 117, 843-856, 575 doi: 10.1175/1520-0493(1989)117<0843:ACSONT>2.0.CO;2.

576 Brooks, H. E., 2009: Proximity soundings for severe convection for Europe and the United States 577 from reanalysis data. Atmos. Res., 93, 546-553, doi:10.1016/j.atmosres.2008.10.005.

578 Brooks, H. E., and C. A. Doswell, 2001: Some aspects of the international climatology of 579 tornadoes by damage classification. Atmos. Res., 56, 191-201, doi: 10.1016/S0169$580 \quad 8095(00) 00098-3$.

581 Brown, M. J., J. D. Locatelli, M. T. Stoelinga, and P. V. Hobbs, 1999: Numerical modeling of 582 precipitation cores on cold fronts. J. Atmos. Sci., 56, 1175-1196. 
583 Browning, K. A., 1990: Organization of clouds and precipitation in extratropical cyclones. 584 Extratropical Cyclones, The Erik Palmén Memorial Volume, C. W. Newton and E. O. 585 Holopainen, Eds., Amer. Meteor. Soc., 129-153.

586 Browning, K. A., and T. W. Harrold, 1970: Air motion and precipitation growth at a cold front. Quart. J. Roy. Meteor. Soc., 96, 369-389.

Browning, K. A., and C. W. Pardoe, 1973: Structure of low-level jet streams ahead of mid-latitude cold fronts. Quart. J. Roy. Meteor. Soc., 99, 619-638.

Browning, K. A., and R. Reynolds, 1994: Diagnostic study of a narrow cold frontal rainband and severe winds associated with a stratospheric intrusion. Quart. J. Roy. Meteor. Soc., $\underline{\mathbf{1 2 0}}$, $235-257$.

Browning, K. A., and N. M. Roberts, 1996: Variation of frontal and precipitation structure along a cold front. Quart. J. Roy. Meteor. Soc., 122, 1845-1872.

Browning, K. A., N. M. Roberts, and A. J. Illingworth, 1997: Mesoscale analysis of the activation of a cold front during cyclogenesis. Quart. J. Roy. Meteor. Soc., 123, 2349-2375.

Carbone, R. E., 1982: A severe frontal rainband. Part I. Stormwide hydrodynamic structure. J. Atmos. Sci., 39, 258-279.

Carbone, R. E., 1983: A severe frontal rainband. Part II. Tornado parent vortex circulation. $J$. Atmos. Sci., 40, 2639-2654.

602

Clark, M. R., 2009: The southern England tornadoes of 30 December 2006: Case study of a 603 tornadic storm in a low CAPE, high shear environment. Atmos. Res., 93, 50-65, doi:10.1016/j.atmosres.2008.10.008. 
604 Clark, M. R., 2011: Doppler radar observations of mesovortices within a cool-season tornadic 605 squall line over the UK. Atmos. Res., 100, 749-764, doi:10.1016/j.atmosres.2010.09.007.

606 Clark, M. R., 2013: A provisional climatology of cool-season convective lines in the UK. Atmos. 607 Res., 123, 180-196, doi:10.1016/j.atmosres.2012.09.018.

608 Clark, M. R., and D. J. Parker, 2014: On the mesoscale structure of surface wind and pressure 609 fields near tornadic and nontornadic cold fronts. Mon. Wea. Rev., 142, 3560- 3585, doi: $610 \quad$ 10.1175/MWR-D-13-00395.1.

611 Craven, J. P., and H. E Brooks, 2004: Baseline climatology of sounding derived parameters 612 associated with deep moist convection. Natl. Wea. Dig., 28, 13-24.

613 Doe, R. K., Ed., 2016: Extreme Weather: Forty Years of the Tornado and Storm Research 614 Organization (TORRO). Wiley Blackwell, 327 pp.

615 Elsom, D. M., G. T. Meaden, D. J. Reynolds, M. W. Rowe, and J. D. C. Webb, 2001: Advances 616 in tornado and storm research in the United Kingdom and Europe: The role of the Tornado 617 and Storm Research Organisation. Atmos. Res., 56, 19-29, doi:10.1016/S0169618 8095(00)00084-3.

619 Fujita, T., 1981: Tornadoes and downbursts in the context of generalized planetary scales. $J$. 620 Atmos. Sci., 38, 1511-1534.

621 Groenemeijer, P., U. Corsmeier, and Ch. Kottmeier, 2011: The development of tornadic storms 622 on the cold side of a front favoured by local enhancement of moisture and CAPE. Atmos. 623 Res., 100, 765-781, doi:10.1016/j.atmosres.2010.10.028.

624 Hagan, M., 1992: On the appearance of a cold front with a narrow rainband in the vicinity of the 625 Alps. Meteor. Atmos. Phys., 48, 231-248. 
626 Hobbs, P. V., and K. R. Biswas, 1979: The cellular nature of narrow cold-frontal rainbands.

627 Quart. J. Roy. Meteor. Soc., 105, 723-727.

628 Hobbs, P. V., and P. O. G. Persson, 1982: The mesoscale and microscale structure and 629 organization of clouds and precipitation in midlatitude cyclones. Part V: The substructure of 630 narrow cold-frontal rainbands. J. Atmos. Sci., 39, 280-295.

631 Holden, J., and A. Wright, 2004: Tornado climatology and the development of simple prediction tools. Quart. J. Roy. Meteor. Soc., 130, 1009-1021, doi: 10.1256/qj.03.45.

Houze, R. A., Jr., 2014: Cloud Dynamics, 2nd ed. Academic Press, 496 pp.

634 James, P. K., and K. A. Browning, 1979: Mesoscale structure of line convection at surface cold 635 fronts. Quart. J. Roy. Meteor. Soc., 105, 371-382.

636 Janjić, Z. I., 1994: The step-mountain eta coordinate model: Further developments of the 637 convection, viscous sublayer and turbulence closure schemes. Mon. Wea. Rev., 122, 9276389 945, doi: 10.1175/1520-0493(1994)122<0927:TSMECM>2.0.CO;2.

639 Janjić, Z. I., 2002: Nonsingular implementation of the Mellor-Yamada level 2.5 scheme in the $640 \quad$ NCEP Meso model. NCEP Office Note, No. 437, 61 pp.

641 Jewett, B. F., and R. B. Wilhelmson, 2006: The role of forcing in cell morphology and evolution 642 within midlatitude squall lines. Mon. Wea. Rev., 134, 3714-3734.

643 Johns, R. H., and C. A. Doswell III, 1992: Severe local storms forecasting. Wea. Forecasting, 7, $644 \quad$ 588-612, doi: 10.1175/1520-0434(1992)007<0588:SLSF>2.0.CO;2.

645 Jorgensen, D. P., Z. Pu, P. O. G. Persson, and W. Tao, 2003: Variations associated with cores 646 and gaps of a Pacific narrow cold frontal rainband. Mon. Wea. Rev., 131, 2705-2729, doi: $647 \quad 10.1175 / 1520-0493(2003) 131<2705: V A W C A G>2.0 . C O ; 2$. 
648 Kain, J. S., 2004: The Kain-Fritsch convective parameterization: An update. J. Appl. Meteor.,

$649 \quad \mathbf{4 3}, 170-181$, doi: 10.1175/1520-0450(2004)043<0170:TKCPAU>2.0.CO;2.

650 Kain, J. S., and J. M. Fritsch, 1990: A one-dimensional entraining/detraining plume model and

651 its application in convective parameterization. J. Atmos. Sci., 47, 2784-2802, doi: 10.1175/1520-0469(1990)047<2784:AODEPM>2.0.CO;2.

653 Kalnay, E., and Coauthors, 1996: The NCEP/NCAR 40-Year Reanalysis Project. Bull. Amer. $654 \quad$ Meteor. Soc., 77, 437-471.

655 Kawashima, M., 2011: Numerical study of horizontal shear instability waves along narrow cold 656 frontal rainbands. J. Atmos. Sci., 68, 878-903.

657 Kemp, A. K., and S. J. Morris, 1982: Line squall and minor tornadoes at Holyhead, 23 $658 \quad$ November 1981. Meteor. Mag., 111, 253-261.

659 Kirk, P. J., 2014: An updated tornado climatology for the UK: 1981-2010. Weather, 69, 171$660 \quad 175$.

661 Kobayashi, F., Y. Sugawara, M. Imai, M. Matsui, A. Yoshida, and Y. Tamura, 2007: Tornado 662 generation in a narrow cold frontal rainband-Fujisawa tornado on April 20, 2006-. SOLA, $663 \quad 3,21-24$.

664 Lee, B. D., and R. B. Wilhelmson, 1997a: The numerical simulation of non-supercell 665 tornadogenesis. Part I: Initiation and evolution of pretornadic misocyclone and circulations 666 along a dry outflow boundary. J. Atmos. Sci., 54, 32-60.

667 Lee, B. D., and R. B. Wilhelmson, 1997b: The numerical simulation of nonsupercell 668 tornadogenesis. Part II: Evolution of a family of tornadoes along a weak outflow boundary. $J$. 669 Atmos. Sci., 54, 2387-2415. 
670 Lee, B. D., and R. B. Wilhelmson, 2000: The numerical simulation of nonsupercell 671 tornadogenesis. Part III: Parameter tests investigating the role of CAPE, vortex sheet 672 strength, and boundary layer vertical shear. J. Atmos. Sci., 57, 2246-2261.

673 Locatelli, J. D., J. E. Martin, and P. V. Hobbs, 1995: Development and propagation of 674 precipitation cores on cold fronts. Atmos. Res., 38, 177-206.

675 Markowski, P. M., J. M. Straka, and E. N. Rasmussen, 2002: Direct surface thermodynamic 676 observations within the rear-flank downdrafts of nontornadic and tornadic supercells. Mon. 677 Wea. Rev., 130, 1692-1721, doi: 10.1175/1520-0493(2002)130<1692:DSTOWT>2.0.CO;2.

678 McAvoy, B. P., W. A. Jones, and P. D. Moore, 2000: Investigation of an unusual storm structure 679 associated with weak to occasionally strong tornadoes over the eastern United States. 680 Preprints, 20th Severe Local Storms Conference, Orlando, FL, Amer. Meteor. Soc., 182-185.

681 Meaden, G. T., 1983: The TORRO tornado intensity scale. J. Meteor. (UK), 8, 151-153.

682 Meaden, G. T., S. Kochev, L. Kolendowicz, A. Kosa-Kiss, I. Marcinoniene, M. Sioutas, H. 683 Tooming, and J., Tyrrell, 2007: Comparing the theoretical versions of the Beaufort scale, the 684 T-Scale and the Fujita scale. Atmos. Res., 83, 446-449, doi:10.1016/j.atmosres.2005.11.014.

685 Mellor, G. L., and T. Yamada, 1982: Development of a turbulence closure model for geophysical 686 fluid problems. Rev. Geophys. Space Phys., 20, 851-875.

687 Morrison, H., G. Thompson, and V. Tatarskii, 2009: Impact of cloud microphysics on the 688 development of trailing stratiform precipitation in a simulated squall line: Comparison of 689 one- and two-moment schemes. Mon. Wea. Rev., 137, 991-1007.

690 Mulder, K. J., 2015: Tornadoes in the British Isles: Climatology, formation environments, and 691 storm dynamics. Ph.D. dissertation, University of Manchester, 96 pp. 
692 Mulder, K. J., and D. M. Schultz, 2015: Climatology, storm morphologies, and environments of 693 tornadoes in the British Isles: 1980-2012. Mon. Wea. Rev., 143, 2224-2240.

694 Nolen, R. H., 1959: A radar pattern associated with tornadoes. Bull. Amer. Meteor. Soc., 40, $695 \quad 277-279$.

696 Potvin, C. K., K. L. Elmore, and S. J. Weiss, 2010: Assessing the impacts of proximity sounding 697 criteria on the climatology of significant tornado environments. Wea. Forecasting, 25, 921698930.

699 Púčik, T., P. Groenemeijer, D. Rýva, and M. Kolář, 2015: Proximity soundings of severe and 700 nonsevere thunderstorms in Central Europe. Mon. Wea. Rev., 143, 4805-4821.

701 Rasmussen, E. N., and D. O. Blanchard, 1998: A baseline climatology of sounding-derived 702 supercell and tornado forecast parameters. Wea. Forecasting, 13, 1148-1164.

703 Roebber, P. J., D. M. Schultz, and R. Romero, 2002: Synoptic regulation of the 3 May 1999 704 tornado outbreak. Wea. Forecasting, 17, 399-429.

705 Rowe, M. W., 1985: Britain's greatest tornadoes and tornado outbreak. J. Meteor. (UK), 10, $706 \quad 212-220$.

707 Rowe, M. W., 2016: Tornado extremes in the United Kingdom: The earliest, longest, widest, 708 severest, and deadliest. Extreme Weather: Forty Years of the Tornado and Storm Research 709 Organization (TORRO). R. K. Doe, Ed., Wiley Blackwell, 77-90.

710 Rowe, M. W., and G. T. Meaden, 1985: Britain's greatest tornado outbreak. Weather, 40, 230$711 \quad 235$, doi: 10.1002/j.1477-8696.1985.tb06883.x. 
712 Skamarock, W. C., J. B. Klemp, J. Dudhia, D. O. Gill, D. M. Barker, M. G. Duda, X.-Y. Huang,

713 W. Wang, and J. G. Powers, 2008: A description of the Advanced Research WRF Version 3.

714 NCAR technical note, NCAR/TN-475+STR, 113 pp.

715 Smart, D. J., and K. A. Browning, 2009: Morphology and evolution of cold-frontal 716 misocyclones. Quart. J. Roy. Meteor. Soc., 135, 381-393, doi: 10.1002/qj.399.

717 Smith, B. T., R. L. Thompson, J. S. Grams, C. Broyles, and H. E. Brooks, 2012: Convective 718 modes for significant severe thunderstorms in the contiguous United States. Part I: Storm 719 classification and climatology. Wea. Forecasting, 27, 1114-1135, doi: 10.1175/WAF-D-11$720 \quad \underline{00115.1}$.

721 Speheger, D. A., C. A. Doswell III, and G. J. Stumpf, 2002: The tornadoes of 3 May 1999: 722 Event verification in central Oklahoma and related issues. Wea. Forecasting, 17, 362-381.

723 Sugawara, Y., and F. Kobayashi, 2009: Vertical structure of misocyclones along a narrow cold 724 frontal rainband. J. Meteor. Soc. Japan, 87, 497-503.

725 Thompson, G., P. R. Field, R. M. Rasmussen, and W. D. Hall, 2008: Explicit forecasts of winter 726 precipitation using an improved bulk microphysics scheme. Part II: Implementation of a new 727 snow parameterization. Mon. Wea. Rev., 136, 5095-5115, doi:10.1175/2008MWR2387.1.

728 Thompson, R. L., R. Edwards, J. A. Hart, K. L. Elmore, and P. Markowski, 2003: Close 729 proximity soundings within supercell environments obtained from the Rapid Update Cycle. $730 \quad$ Wea. Forecasting, 18, 1243-1261.

731 Thompson, R. L., B. T. Smith, J. S. Grams, A. R. Dean, and C. Broyles, 2012: Convective modes 732 for significant severe thunderstorms in the contiguous United States. Part II: Supercell and 733 QLCS tornado environments. Wea. Forecasting, 27, 1136-1154. 
734 Trapp, R. J., E. D. Mitchell, G. A. Tipton, D. W. Effertz, A. I. Watson, D. L. Andra Jr., and M. 735 A. Magsig, 1999: Descending and non-descending tornadic vortex signatures detected by 736 WSR-88Ds. Wea. Forecasting, 14, 625-639.

737 Trapp, R. J., S. A. Tessendorf, E. S. Godfrey, and H. E. Brooks, 2005: Tornadoes from squall 738 lines and bow echoes. Part I: Climatological distribution. Wea. Forecasting, 20, 23-34, doi: $739 \quad$ 10.1175/WAF-835.1.

740 Trapp, R. J., and M. L. Weisman, 2003: Low-level mesovortices within squall lines and bow 741 echoes. Part II: Their genesis and implications. Mon. Wea. Rev., 131, 2804-2823.

742 Trapp, R. J., D. M. Wheatley, N. T. Atkins, R. W. Przybylinski, and R. Wolf, 2006: Buyer 743 beware: Some words of caution on the use of severe wind reports in postevent assessment 744 and research. Wea. Forecasting, 21, 408-415.

745 Turner, S., Elsom, D. M., and G. T. Meaden, 1986: An outbreak of 31 tornadoes associated with 746 a cold front in southern England on 20 October 1981. J. Meteor. (UK), 11, 37-50.

747 Viale, M., R. A. Houze Jr., and K. L. Rasmussen, 2013: Upstream orographic enhancement of a 748 narrow cold-frontal rainband approaching the Andes. Mon. Wea. Rev., 141, 1708-1730.

749 Wakimoto, R. M., and B. L. Bosart, 2000: Airborne radar observations of a cold front during $750 \quad$ FASTEX. Mon. Wea. Rev., 128, 2447-2470.

751 Wakimoto, R. M., and J. W. Wilson, 1989: Non-supercell tornadoes. Mon. Wea. Rev., 117, $752 \quad 1113-1140$.

753 Weisman, M. L., and R. J. Trapp, 2003: Low-level meso-vortices within squall lines and bow 754 echoes. Part I: Overview and dependence on environmental shear. Mon. Wea. Rev., 131, $755 \quad 2779-2803$. 
756 Wheatley, D. M., and R. J. Trapp, 2008: The effect of mesoscale heterogeneity on the genesis 757 and structure of mesovortices within quasi-linear convective systems. Mon. Wea. Rev., 136, $758 \quad 4220-4241$. FIGURE CAPTIONS

761 Figure 1. Locations of the 104 tornado reports from the TORRO database for 23 November

762 1981. Numbers represent their strength on the $\mathrm{T}$ scale; $\mathrm{U}$ represents unknown intensity, and 763 half-values represent intensities between two classes (e.g., 2.5 represents T2-T3). Reports 764 verified by TORRO (58) are classified as definite and plotted in black. Reports that have not 765 been verified (46) are classified as probable and are plotted in red. Locations discussed in the 766 text are labeled in blue. Locations of reports that appear to be located over water are a result of a 767 coarse representation of geography.

768 Figure 2. Distribution on the $\mathrm{T}$ scale of intensities of the 99 tornado reports on 23 November 7691981 associated with an intensity rating from the TORRO database.

770 Figure 3. Excerpts from Met Office Daily Weather Summary surface weather charts at (a) 1200

771 UTC 22 November 1981 and (b) 1200 UTC 23 November 1981. Plotted are sea level pressure 772 contours every $4 \mathrm{hPa}$, surface fronts, surface temperatures $\left({ }^{\circ} \mathrm{C}\right)$ and weather at selected cities, 773 and occasionally wind barbs (standard notation). Crown copyright.

774 Figure 4. Excerpt from Met Office Daily Weather Summary 500-hPa chart at 1200 UTC 23

775 November 1981. Plotted are 500-hPa geopotential height (solid lines every 6 dam) and 1000-

776 500-hPa thickness (dashed lines every 6 dam). Crown copyright. 
777 Figure 5. Excerpts from the Met Office Central Forecasting Office hourly U.K. working charts at 778 (a) 1000 UTC, (b) 1200 UTC, and 1400 UTC 23 November 1981. Plotted are sea-level pressure 779 (solid lines every $2 \mathrm{hPa}$ in (a) and (c) and $4 \mathrm{hPa}$ in (b)), cold front (dashed line), and standard 780 station models. Crown copyright.

781 Figure 6. Hourly rainfall amounts (mm) from 213 rain gauges ending at 1200 UTC and 212 rain 782 gauges ending at 1400 UTC 23 Nov 1981.

783 Figure 7. Infrared satellite imagery (channel 5, 11.5-12.5 $\mu \mathrm{m}$ ) at 1325 UTC 23 Nov 1981 784 (courtesy of Dundee Satellite Receiving Station).

785 Figure 8. Prefrontal sounding from Aughton, near Liverpool, at 0000 UTC 23 November 1981 786 (courtesy of the University of Wyoming, http://weather.uwyo.edu/upperair/sounding.html).

787 Figure 9. The two innermost domains used in this simulation.

788 Figure 10. Simulation of sea level pressure (hPa, blue lines), surface temperature $\left({ }^{\circ} \mathrm{C}\right.$, colored 789 according to scale), and surface winds (pennant, full barb, and half-barb denote $25,5,2.5 \mathrm{~m} \mathrm{~s}^{-1}$, 790 respectively; separation between displayed wind vectors is $30 \mathrm{~km}$ ) on the domain with $1-\mathrm{km}$ 791 horizontal grid spacing at (a) 1000 UTC and (b) 1400 UTC 23 November 1981.

792 Figure 11. Simulation of radar reflectivity factor (dBZ, colored according to scale) and surface 793 winds (pennant, full barb, and half-barb denote 25, 5, 2.5 $\mathrm{m} \mathrm{s}^{-1}$, respectively; separation between 794 displayed wind vectors is $30 \mathrm{~km}$ ) on the domain with $1-\mathrm{km}$ horizontal grid spacing at (a) 1000 795 UTC and (b) 1400 UTC 23 November 1981. 


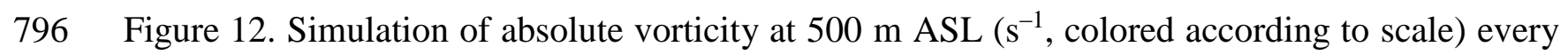
$79730 \mathrm{~min}$ from 0930 UTC to 1730 UTC (labeled every hour) on the domain with 1-km horizontal 798 grid spacing. The red box indicates the location of the domain with 200-m horizontal grid 799 spacing.

800 Figure 13. Simulation of CAPE ( $\mathrm{J} \mathrm{kg}^{-1}$, colored according to scale) and surface winds (pennant, 801 full barb, and half-barb denote $25,5,2.5 \mathrm{~m} \mathrm{~s}^{-1}$, respectively; separation between displayed wind 802 vectors is $30 \mathrm{~km}$ ) on the domain with 1-km horizontal grid spacing at (a) $1000 \mathrm{UTC}$ and (b) 1400 803 UTC 23 November 1981.

804 Figure 14. Simulation of lifting condensation level (LCL) (m, colored according to scale) and 805 surface winds (pennant, full barb, and half-barb denote $25,5,2.5 \mathrm{~m} \mathrm{~s}^{-1}$, respectively; separation 806 between displayed wind vectors is $30 \mathrm{~km}$ ) on the domain with 1-km horizontal grid spacing at (a) 8071000 UTC and (b) 1400 UTC 23 November 1981.

808 Figure 15. Simulation of $0-1-\mathrm{km}$ vertical shear of the horizontal wind in magnitude $\left(\mathrm{m} \mathrm{s}^{-1}\right.$, 809 colored according to scale) and direction (pennant, full barb, and half-barb denote 25, 5, $2.5 \mathrm{~m} \mathrm{~s}^{-}$

810 ', respectively; separation between displayed wind vectors is $30 \mathrm{~km}$ ) on the domain with 1-km 811 horizontal grid spacing at (a) 1000 UTC and (b) 1400 UTC 23 November 1981.

812 Figure 16. Simulation of 0-1-km storm-relative helicity $\left(\mathrm{m}^{2} \mathrm{~s}^{-2}\right.$, colored according to scale) and 813 surface winds (pennant, full barb, and half-barb denote $25,5,2.5 \mathrm{~m} \mathrm{~s}^{-1}$, respectively; separation 814 between displayed wind vectors is $30 \mathrm{~km}$ ) on the domain with 1-km horizontal grid spacing at (a) 8151000 UTC and (b) 1400 UTC 23 November 1981. 
816 Figure 17. Simulation of radar reflectivity factor (black lines every $10 \mathrm{dBZ}$ ), absolute vorticity at

$817500 \mathrm{~m}$ ASL (positive values are contoured in dark blue solid lines every $0.005 \mathrm{~s}^{-1}$, starting from

$8180.01 \mathrm{~s}^{-1}$; negative values are contoured in light blue solid lines every $-0.005 \mathrm{~s}^{-1}$ every $0.005 \mathrm{~s}^{-1}$ ),

819 500-m updrafts (red fill above $5 \mathrm{~m} \mathrm{~s}^{-1}$ ), and 500-m downdrafts (green fill above $2 \mathrm{~m} \mathrm{~s}^{-1}$ ) from the

820 200-m horizontal grid spacing domain, plotted every minute from 1431:50 to 1434:50 UTC 23

$821 \quad$ November 1981.

822 Figure 18. Characteristic structure and evolution of a simulated misovortex within the domain at 823 200-m horizontal grid spacing, plotted every $60 \mathrm{~s}$ around the time that it matures: radar 824 reflectivity factor (dBZ, colored according to scale in Fig. 16), absolute vorticity at $500 \mathrm{~m}$ ASL 825 (black contours every $0.005 \mathrm{~s}^{-1}$, starting from $0.01 \mathrm{~s}^{-1}$ ), 500 -m updraft (red contours every $5 \mathrm{~m} \mathrm{~s}^{-}$ $826^{1}$ ), and 500-m downdraft (pink contours every $2 \mathrm{~m} \mathrm{~s}^{-1}$ ). Each panel is about $4 \mathrm{~km} \times 4 \mathrm{~km}$, and 827 the vortex is about $500 \mathrm{~m}$ across.

828 Figure 19. Locations of the 90 revised tornado reports from the TORRO database for 23 829 November 1981. Numbers represent their strength on the T scale. Reports verified by TORRO 830 (58) are classified as definite and plotted in black. Reports that have not been verified (32) are 831 classified as probable and are plotted in red. Locations discussed in the text are labeled in blue. 832 The red box indicates the location of the domain with 200-m horizontal grid spacing. Locations 833 of reports that appear to be located over water are a result of a coarse representation of 834 geography.

835 Figure 20. Tracks of (a) 500-m absolute vorticity (0.02 and $\left.0.025 \mathrm{~s}^{-1}\right)$, (b) 500-m updrafts $(5,6$, 836 and $\left.7 \mathrm{~m} \mathrm{~s}^{-1}\right)$, and (c) 500-m downdrafts $\left(2,3\right.$, and $\left.4 \mathrm{~m} \mathrm{~s}^{-1}\right)$ plotted every minute from 1300 to 8371600 UTC in the domain with 200-m horizontal grid spacing. 
838 Figure 21. Simulation of $0.02 \mathrm{~s}^{-1}$ and $0.025 \mathrm{~s}^{-1}$ absolute vorticity at $500 \mathrm{~m}$ ASL (black contours),

$8395 \mathrm{~m} \mathrm{~s}^{-1}$ updrafts at $500 \mathrm{~m}$ (red contours), and $3 \mathrm{~m} \mathrm{~s}^{-1}$ downdrafts at $500 \mathrm{~m}$ (green contours) from

8401300 to 1600 UTC on the domain with 200 -m horizontal grid spacing.

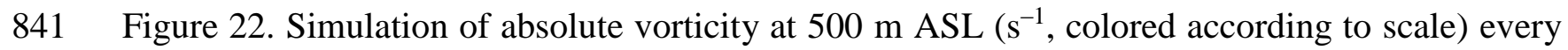
$84230 \mathrm{~min}$ from 0930 UTC to 1730 UTC on the domain with 1-km horizontal grid spacing. Purple

843 lines separate approximate areas with simulated absolute vorticity less than $0.002 \mathrm{~s}^{-1}$ on the $1-\mathrm{km}$

844 domain during the time of frontal passage. Blue lines separate approximate areas with simulated

845 positive CAPE during the time of frontal passage. Locations of reports that appear to be located

846 over water are a result of a coarse representation of geography. Locations of the 90 tornado

847 reports from the TORRO database for 23 November 1981. Numbers represent their strength on

848 the T scale. Reports verified by TORRO (58) are classified as definite and plotted in black.

849 Reports that have not been verified (32) are classified as probable and are plotted in red. 
851 Table 1: Properties of tracks of 500-m absolute vorticity $\left(0.02\right.$ and $\left.0.025 \mathrm{~s}^{-1}\right)$, updrafts $(5,6$, and

$\left.8527 \mathrm{~ms}^{-1}\right)$, and downdrafts $\left(2,3\right.$, and $\left.4 \mathrm{~m} \mathrm{~s}^{-1}\right)$ in the domain with 200-m horizontal grid spacing

853 between 1300 and 1600 UTC. "Long-lived" refers to features lasting 30 min or more ( \pm 2 min

854 because the data interval is every minute). The longest duration track being listed as "101+"

855 means that a track started within the plotting domain but continued to the edge of the domain,

856 indicating that thetrack could have existed longer than $101 \mathrm{~min}$. "N/A" represents no features

857 meeting the designated criteria.

\begin{tabular}{|c|c|c|c|c|c|}
\hline & $\begin{array}{l}\text { Number of } \\
\text { long-lived } \\
\text { maxima }\end{array}$ & $\begin{array}{l}\text { Average } \\
\text { duration of } \\
\text { long-lived } \\
\text { tracks } \\
\text { (min) }\end{array}$ & $\begin{array}{l}\text { Median } \\
\text { duration of } \\
\text { long-lived } \\
\text { tracks } \\
\text { (min) }\end{array}$ & $\begin{array}{l}\text { Longest } \\
\text { duration } \\
\text { track } \\
(\text { min) }\end{array}$ & $\begin{array}{l}\text { Longest } \\
\text { track } \\
\text { length } \\
\text { (to neares } \\
5 \mathrm{~km})\end{array}$ \\
\hline $\begin{array}{l}\text { Vorticity } \\
\left(>0.025 \mathrm{~s}^{-1}\right) \\
\text { tracks }\end{array}$ & 9 & 33.2 & 33 & 38 & 45 \\
\hline $\begin{array}{l}\text { Vorticity } \\
\left(>0.02 \mathrm{~s}^{-1}\right) \\
\text { tracks }\end{array}$ & 41 & 40.3 & 37 & 64 & 75 \\
\hline $\begin{array}{l}\text { Updrafts } \\
(>5 \mathrm{~m} / \mathrm{s}) \\
\text { tracks }\end{array}$ & 23 & 55.3 & 48 & $101+$ & 175 \\
\hline $\begin{array}{l}\text { Updrafts } \\
(>6 \mathrm{~m} / \mathrm{s}) \\
\text { tracks }\end{array}$ & 5 & 54.2 & 56 & 76 & 100 \\
\hline $\begin{array}{l}\text { Updraft } \\
(>7 \mathrm{~m} / \mathrm{s}) \\
\text { tracks }\end{array}$ & 0 & N/A & N/A & 28 & 35 \\
\hline $\begin{array}{l}\text { Downdrafts } \\
(>2 \mathrm{~m} / \mathrm{s}) \\
\text { tracks }\end{array}$ & 10 & 34.2 & 33.5 & 40 & 75 \\
\hline $\begin{array}{l}\text { Downdrafts } \\
(>3 \mathrm{~m} / \mathrm{s}) \\
\text { tracks }\end{array}$ & 0 & N/A & N/A & 22 & 35 \\
\hline $\begin{array}{l}\text { Downdrafts } \\
(>4 \mathrm{~m} / \mathrm{s}) \\
\text { tracks }\end{array}$ & 0 & N/A & N/A & 12 & 20 \\
\hline
\end{tabular}




\section{Locations of 104 Tornado Reports for 23 Nov 1981}

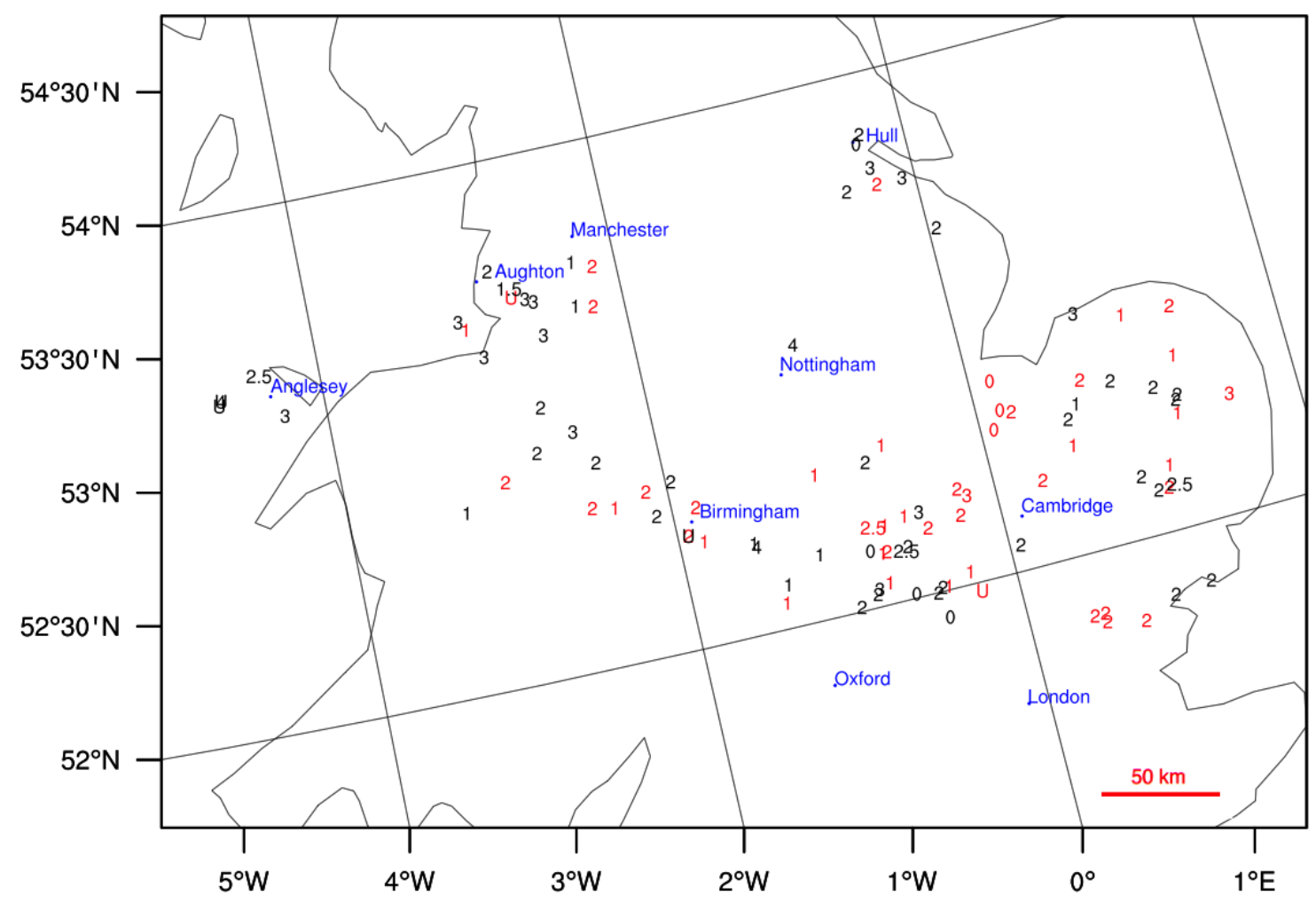

861 Figure 1. Locations of the 104 tornado reports from the TORRO database for 23 November

862 1981. Numbers represent their strength on the T scale; U represents unknown intensity, and

863 half-values represent intensities between two classes (e.g., 2.5 represents T2-T3). Reports

864 verified by TORRO (58) are classified as definite and plotted in black. Reports that have not

865 been verified (46) are classified as probable and are plotted in red. Locations discussed in the

866 text are labeled in blue. Locations of reports that appear to be located over water are a result of a

867 coarse representation of geography. 


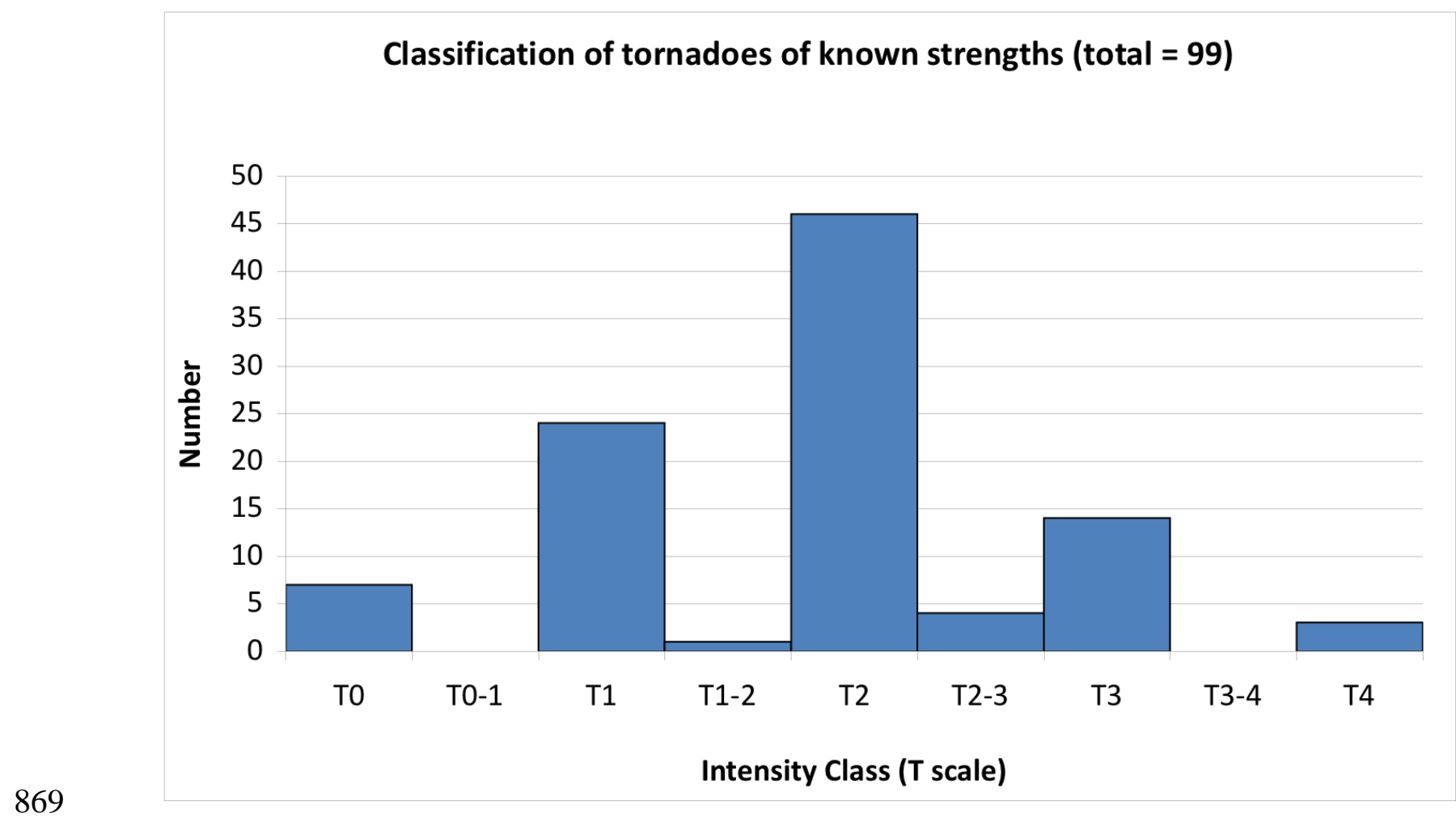

870 Figure 2. Distribution on the T scale of intensities of the 99 tornado reports on 23 November $871 \quad 1981$ associated with an intensity rating from the TORRO database. 

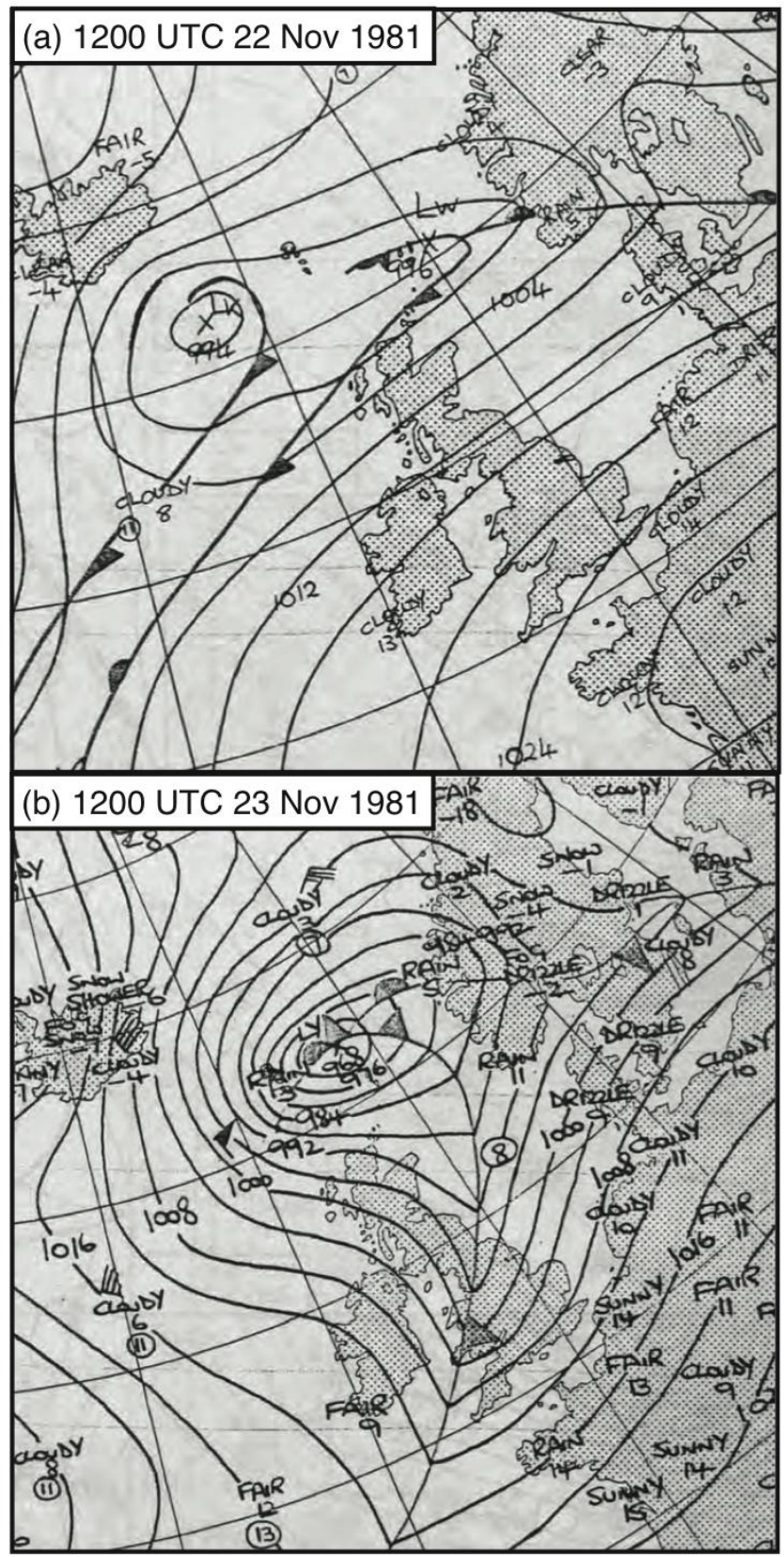

874 Figure 3. Excerpts from Met Office Daily Weather Summary surface weather charts at (a) 1200

875 UTC 22 November 1981 and (b) 1200 UTC 23 November 1981. Plotted are sea level pressure

876 contours every $4 \mathrm{hPa}$, surface fronts, surface temperatures $\left({ }^{\circ} \mathrm{C}\right)$ and weather at selected cities,

877 and occasionally wind barbs (standard notation). Crown copyright. 


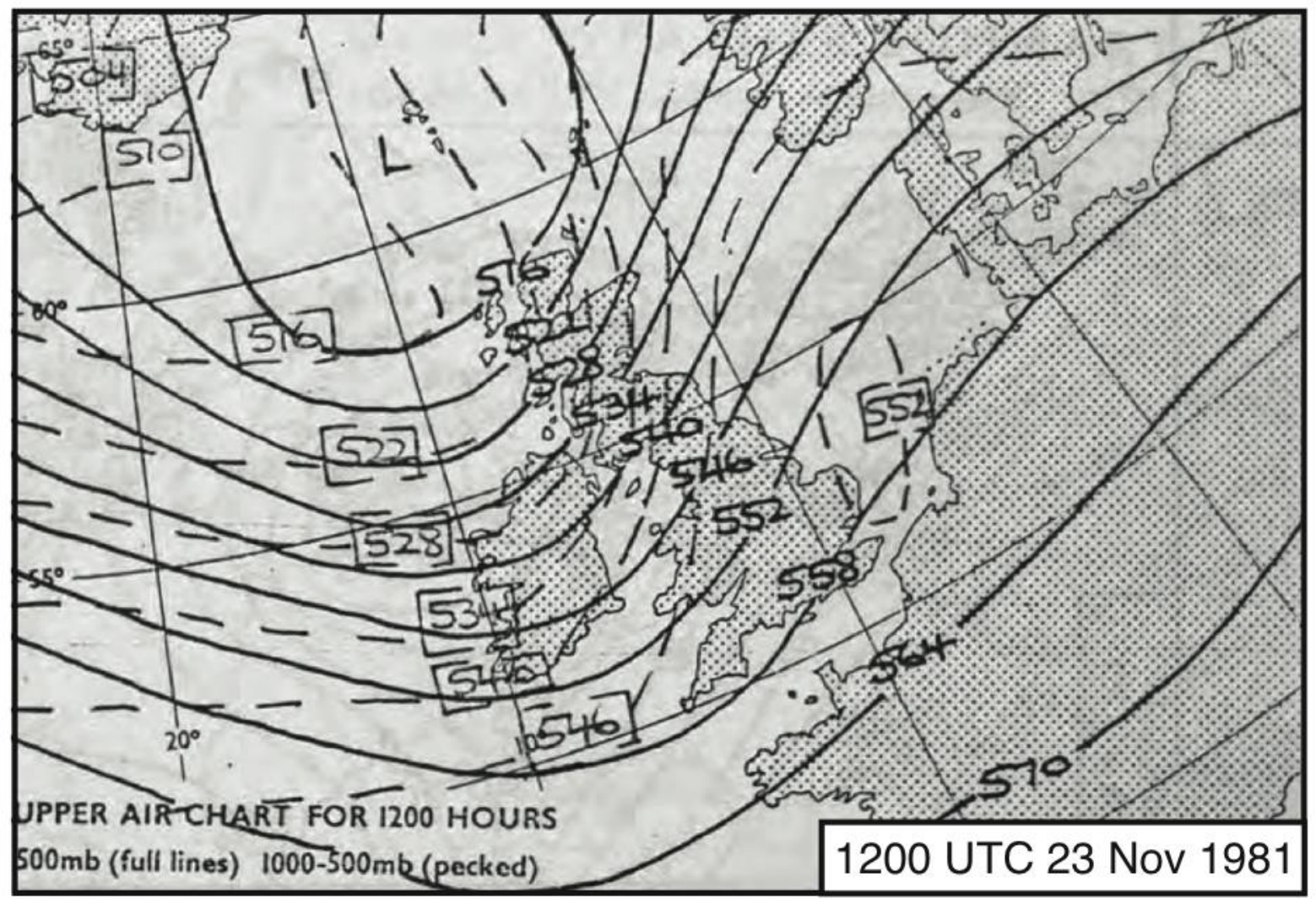

880 Figure 4. Excerpt from Met Office Daily Weather Summary 500-hPa chart at 1200 UTC 23

881 November 1981. Plotted are 500-hPa geopotential height (solid lines every 6 dam) and 1000882 500-hPa thickness (dashed lines every 6 dam). Crown copyright. 


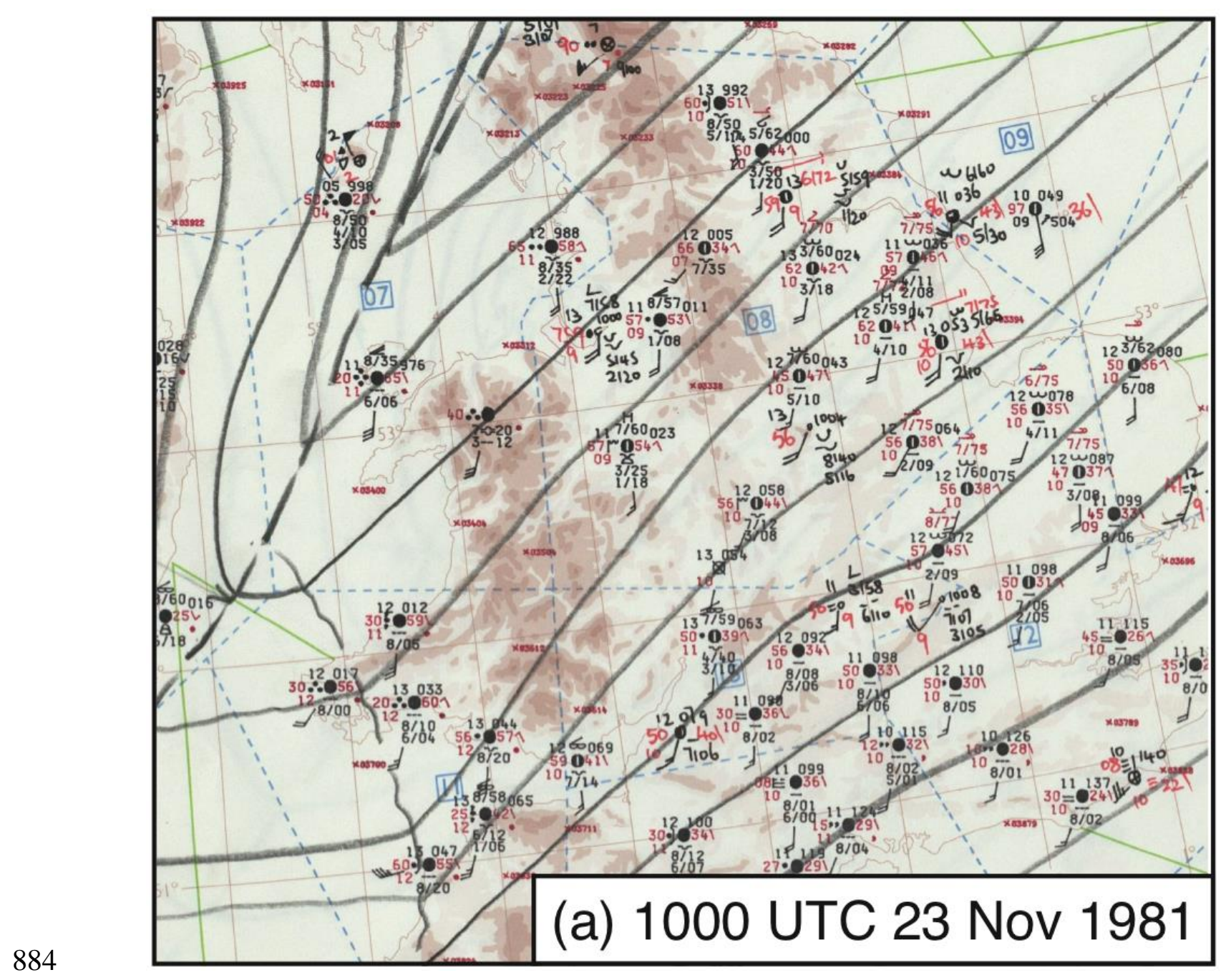

885 


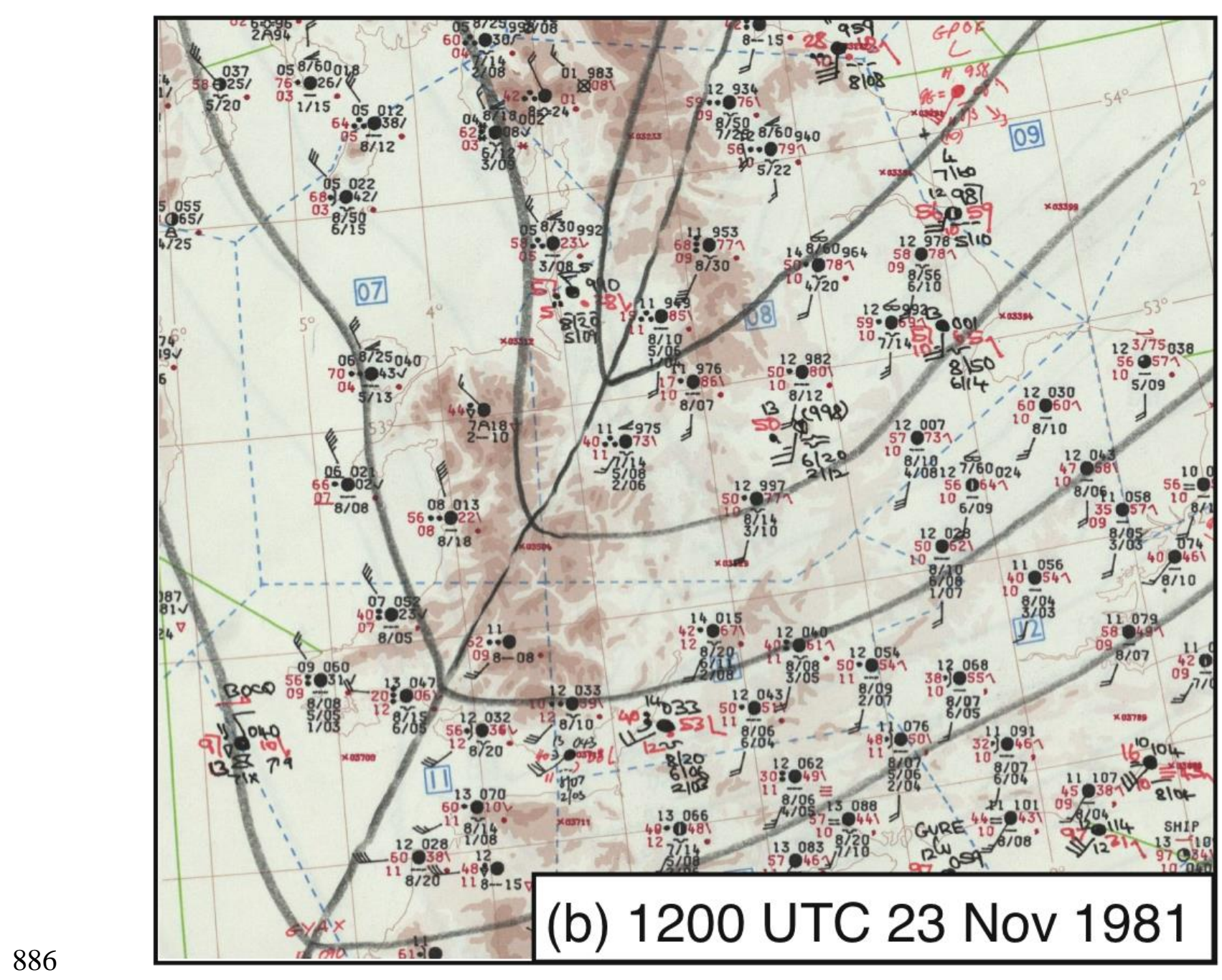

887 


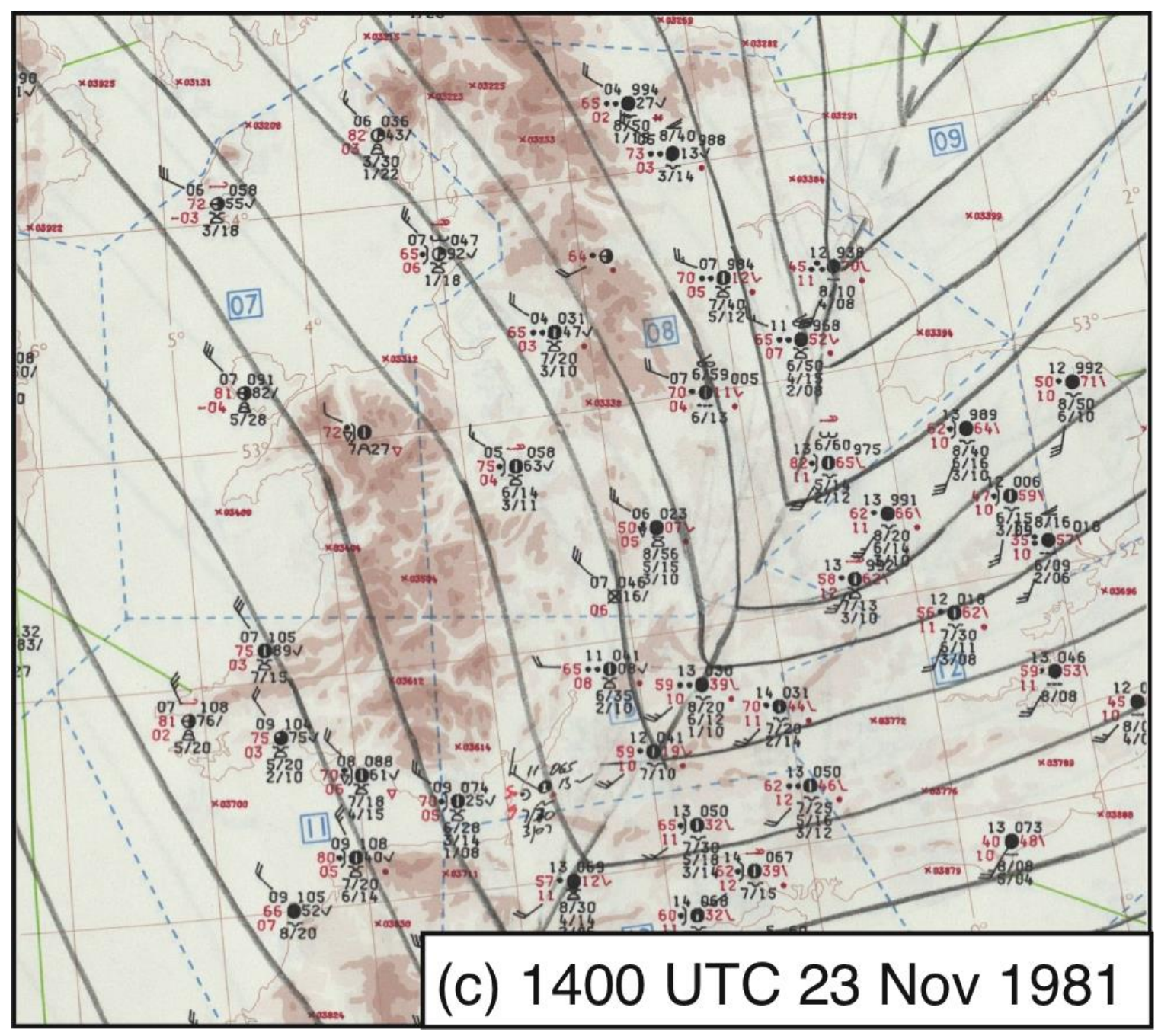

889 Figure 5. Excerpts from the Met Office Central Forecasting Office hourly U.K. working charts at

890 (a) 1000 UTC, (b) 1200 UTC, and 1400 UTC 23 November 1981. Plotted are sea-level pressure

891 (solid lines every $2 \mathrm{hPa}$ in (a) and (c) and $4 \mathrm{hPa}$ in (b)), cold front (dashed line), and standard 892 station models. Crown copyright. 

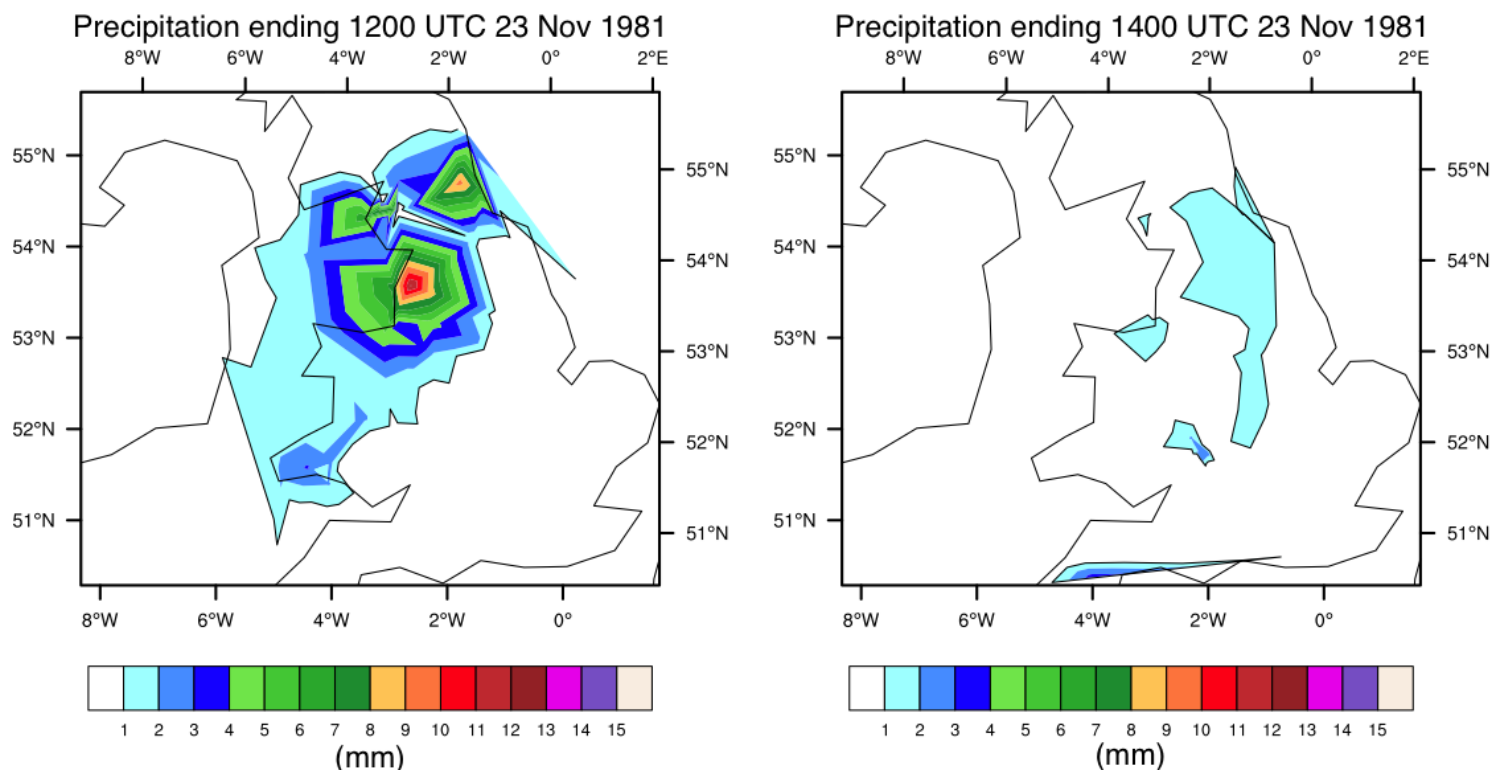

895 Figure 6. Hourly rainfall amounts $(\mathrm{mm})$ from 213 rain gauges ending at 1200 UTC and 212 rain 896 gauges ending at 1400 UTC 23 Nov 1981.

897 


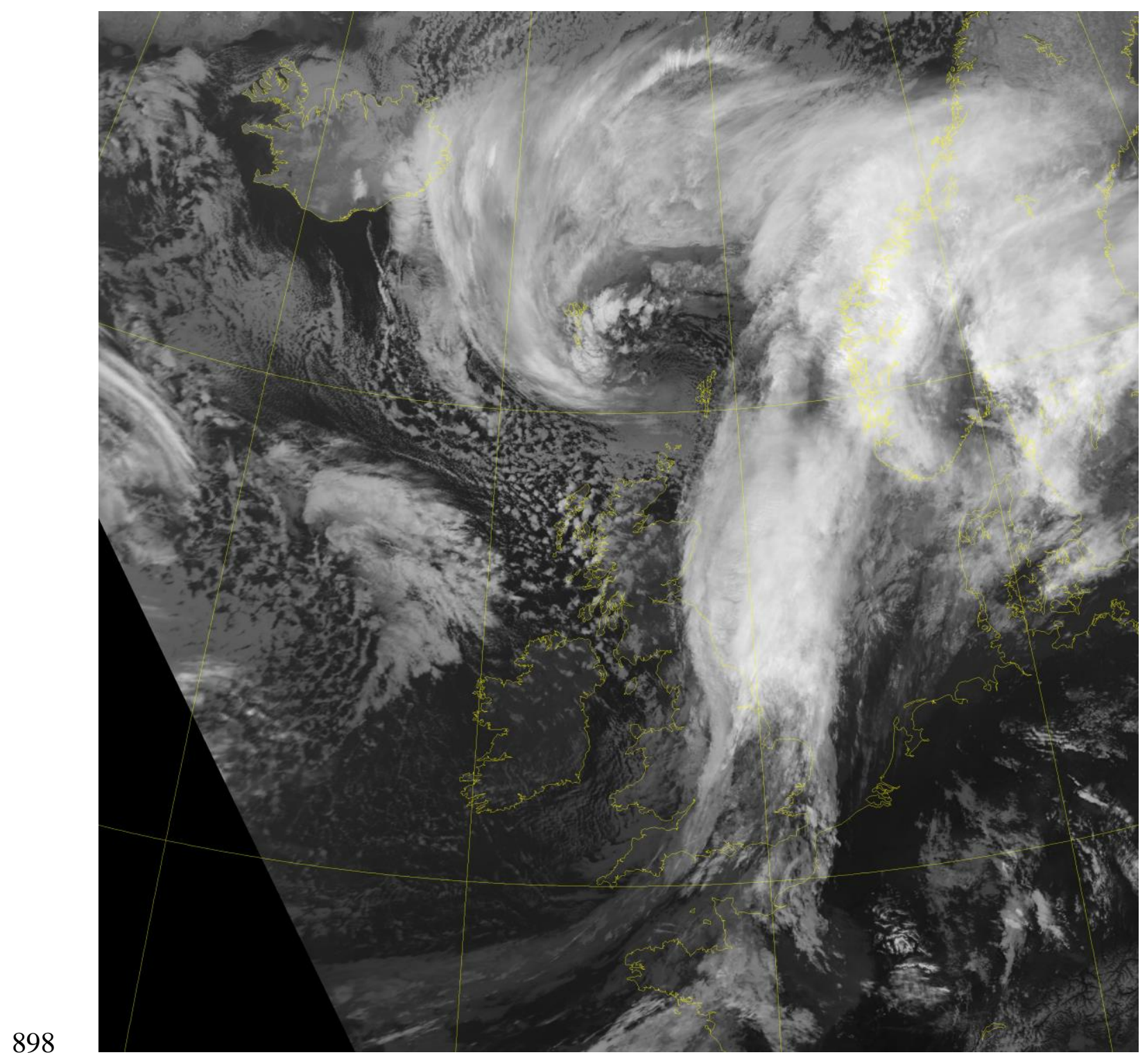

899 Figure 7. Infrared satellite imagery (channel 5, 11.5-12.5 $\mu \mathrm{m}$ ) at 1325 UTC 23 Nov 1981

900 (courtesy of Dundee Satellite Receiving Station).

901

902

903

904 


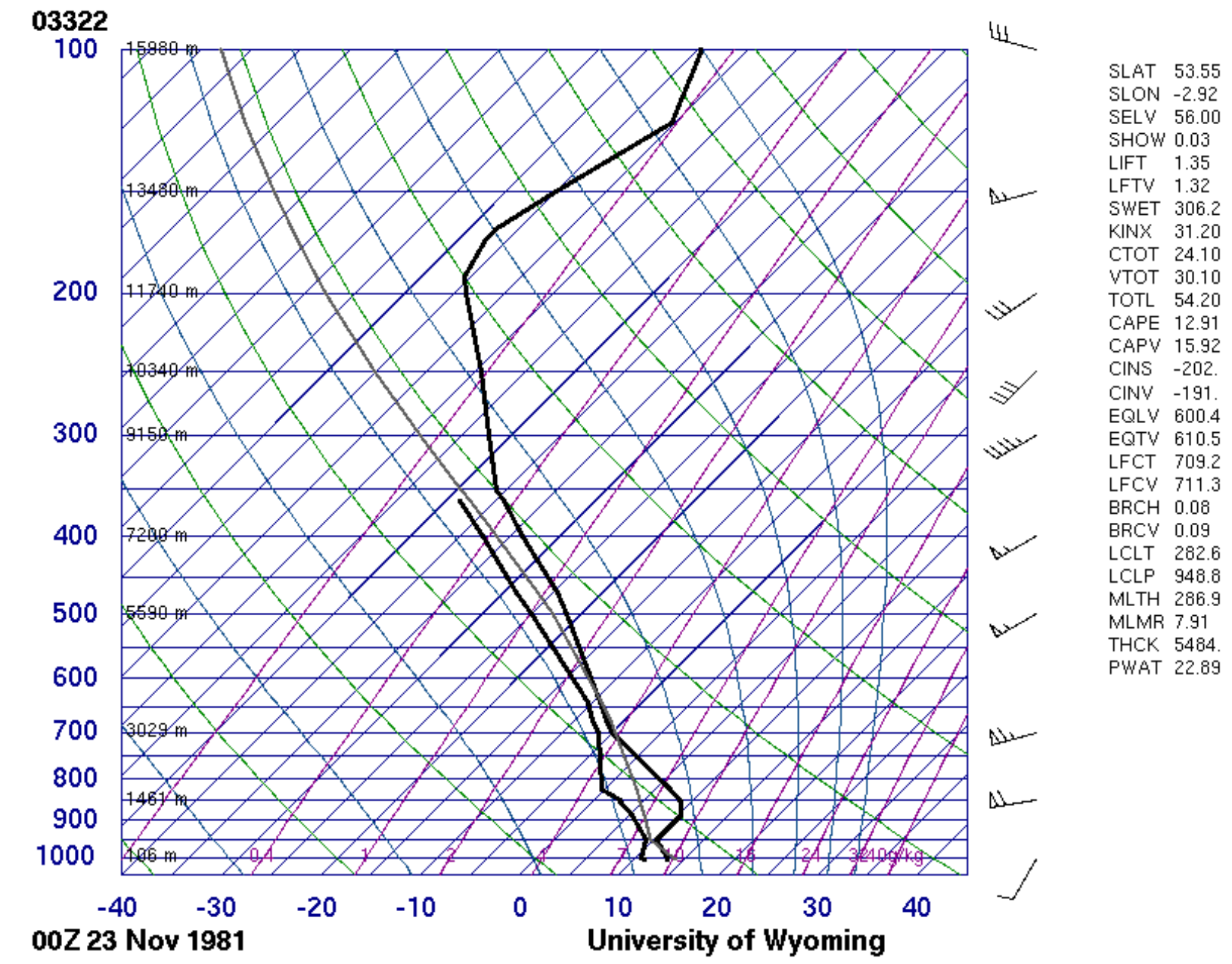

907

908 Figure 8. Prefrontal sounding from Aughton, near Liverpool, at 0000 UTC 23 November 1981

909 (courtesy of the University of Wyoming, http://weather.uwyo.edu/upperair/sounding.html). 


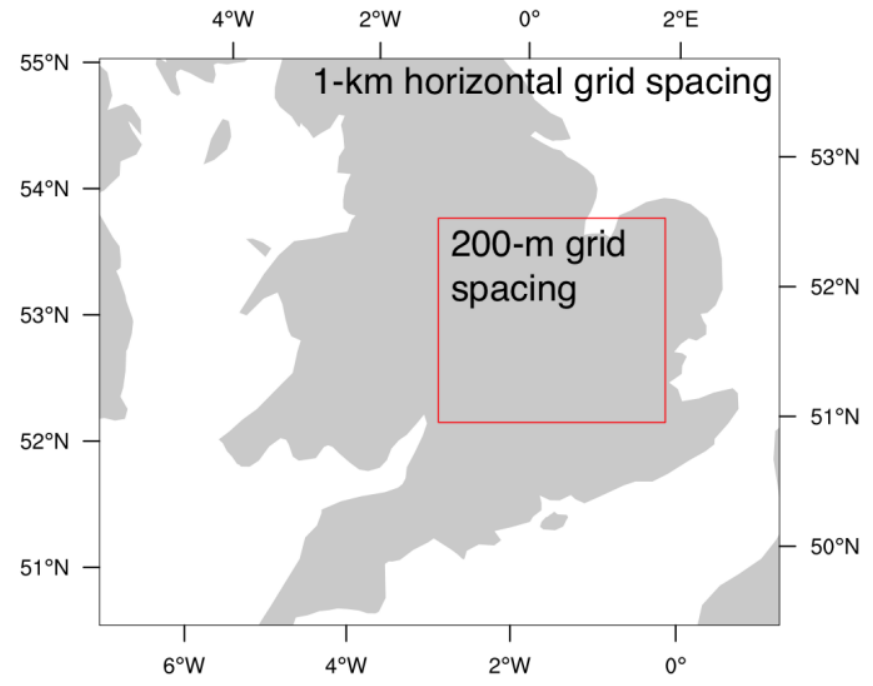

912 Figure 9. The two innermost domains used in this simulation.

913 
914

(a) 1000 UTC

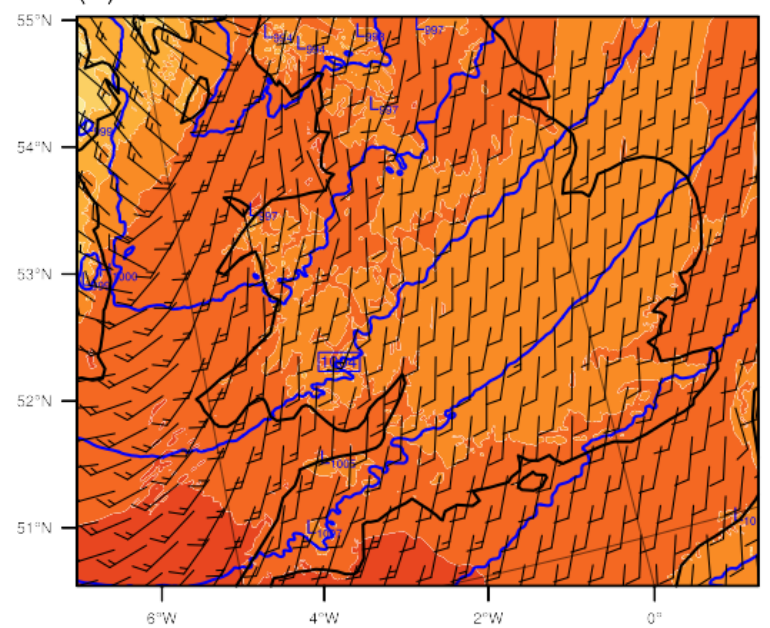

(b) 1400 UTC

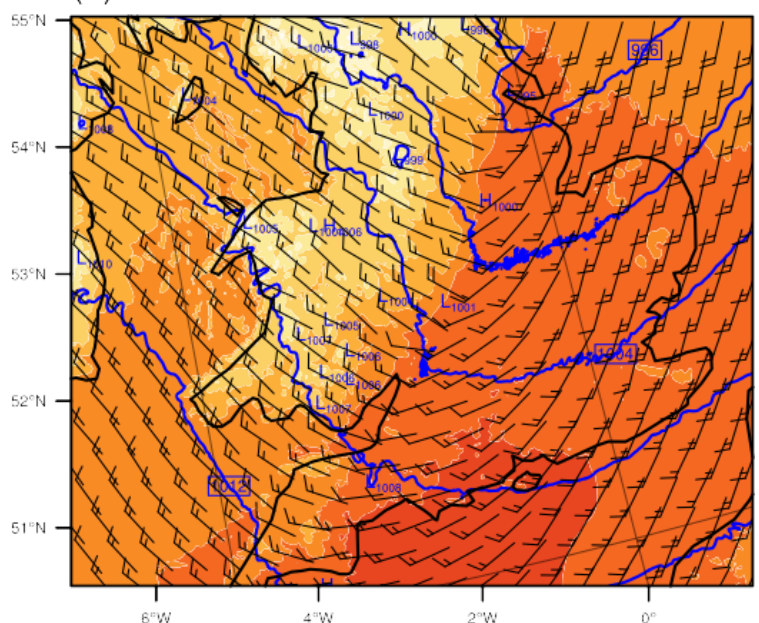

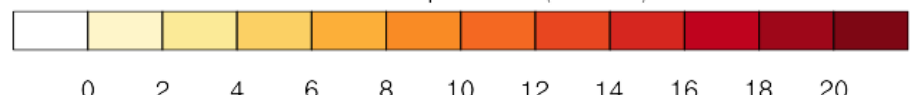

916 Figure 10. Simulation of sea level pressure (hPa, blue lines), surface temperature $\left({ }^{\circ} \mathrm{C}\right.$, colored

917 according to scale), and surface winds (pennant, full barb, and half-barb denote 25, 5, $2.5 \mathrm{~m} \mathrm{~s}^{-1}$,

918 respectively; separation between displayed wind vectors is $30 \mathrm{~km}$ ) on the domain with $1-\mathrm{km}$

919 horizontal grid spacing at (a) 1000 UTC and (b) 1400 UTC 23 November 1981. 
(a) 1000 UTC

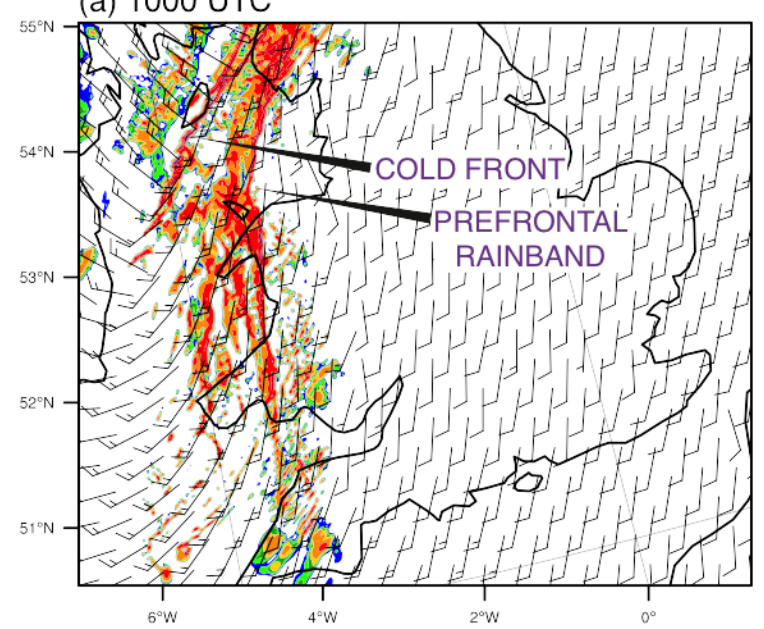

(b) 1400 UTC

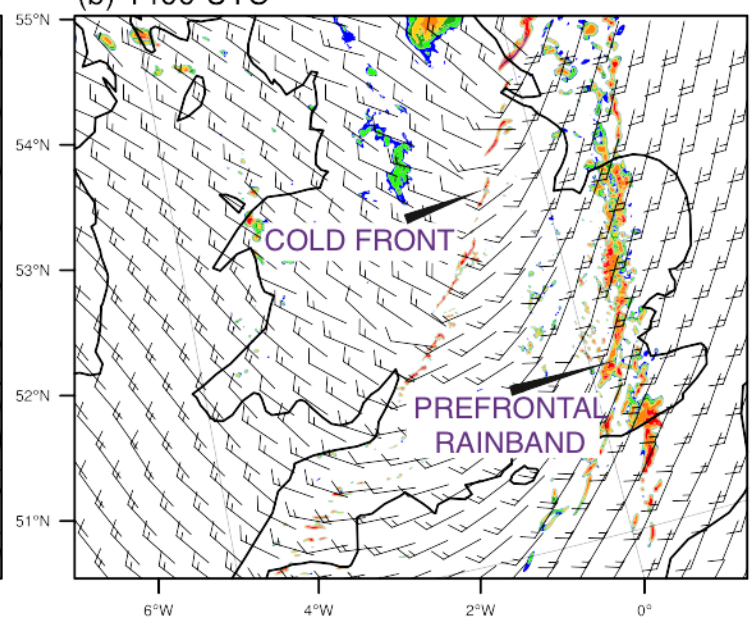

Reflectivity (dBZ)

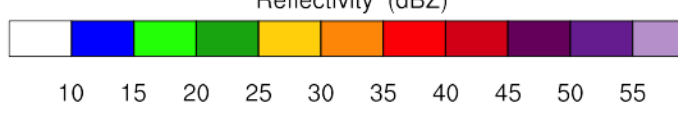

922 Figure 11. Simulation of radar reflectivity factor (dBZ, colored according to scale) and surface

923 winds (pennant, full barb, and half-barb denote 25, 5, $2.5 \mathrm{~m} \mathrm{~s}^{-1}$, respectively; separation between

924 displayed wind vectors is $30 \mathrm{~km}$ ) on the domain with 1-km horizontal grid spacing at (a) 1000

$925 \quad$ UTC and (b) 1400 UTC 23 November 1981. 


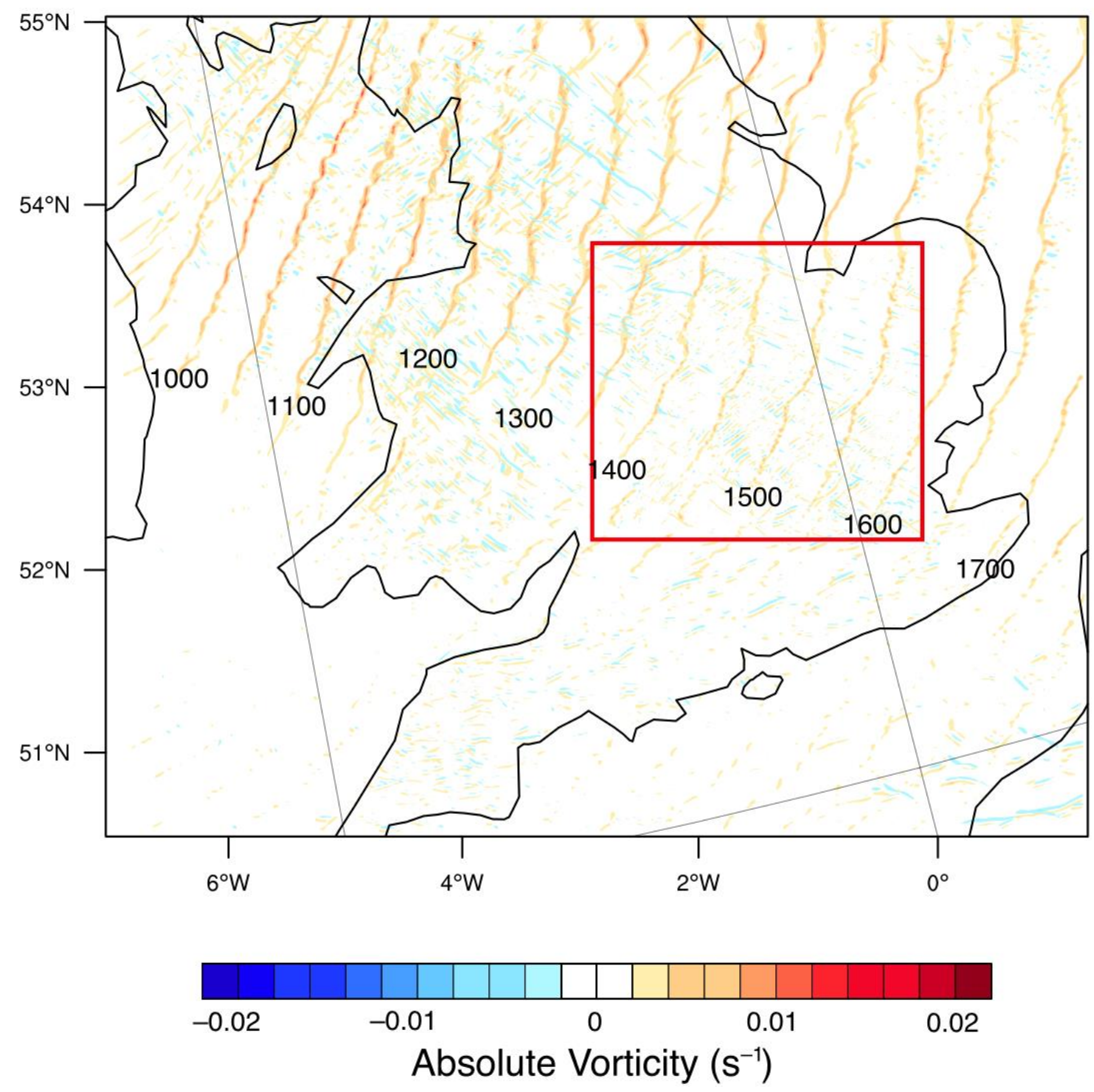

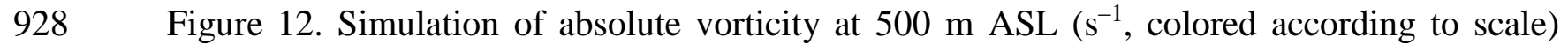
929 every $30 \mathrm{~min}$ from 0930 UTC to 1730 UTC (labeled every hour) on the domain with 1-km

930 horizontal grid spacing. The red box indicates the location of the domain with 200-m 931 horizontal grid spacing. 
(a) 1000 UTC

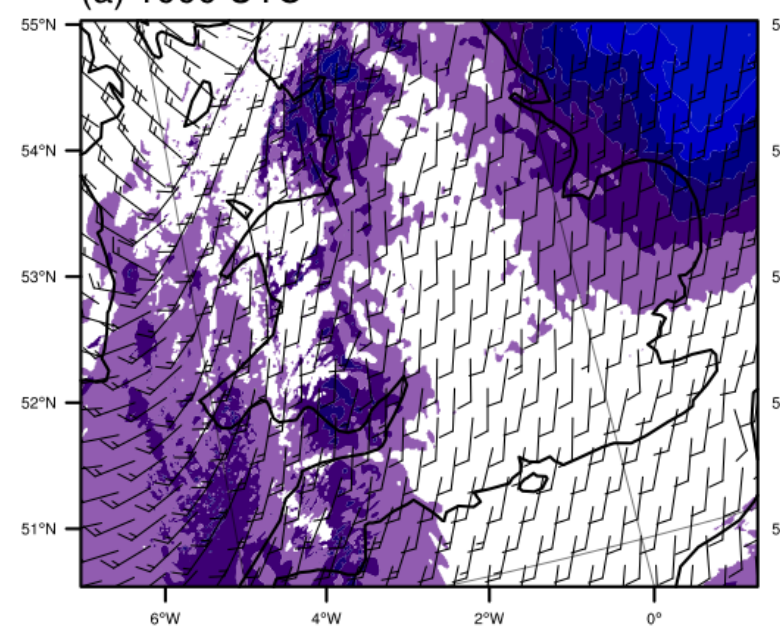

(b) 1400 UTC

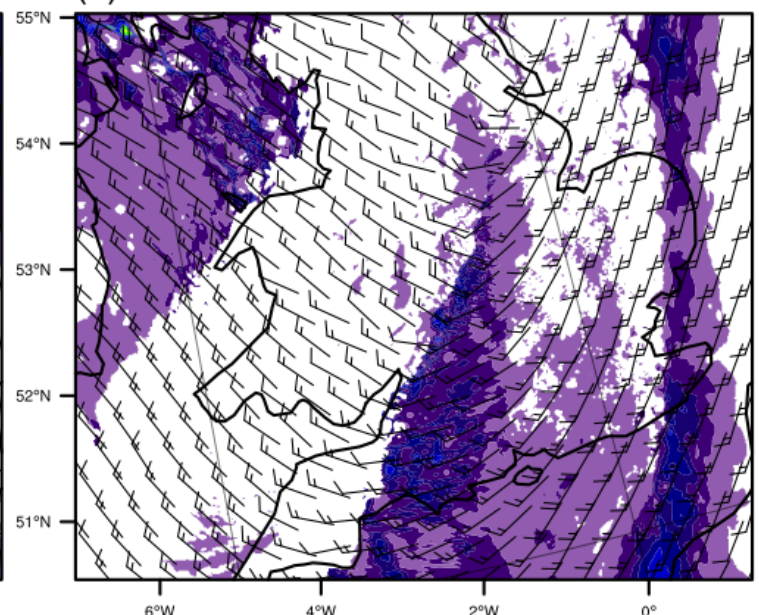

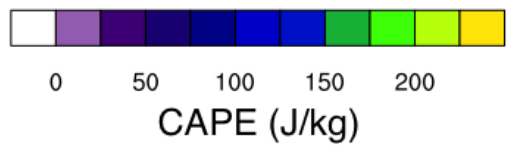

935 Figure 13. Simulation of CAPE $\left(\mathrm{J} \mathrm{kg}^{-1}\right.$, colored according to scale) and surface winds

936 (pennant, full barb, and half-barb denote $25,5,2.5 \mathrm{~m} \mathrm{~s}^{-1}$, respectively; separation between

937 displayed wind vectors is $30 \mathrm{~km}$ ) on the domain with 1-km horizontal grid spacing at (a) 1000

$938 \quad$ UTC and (b) 1400 UTC 23 November 1981. 


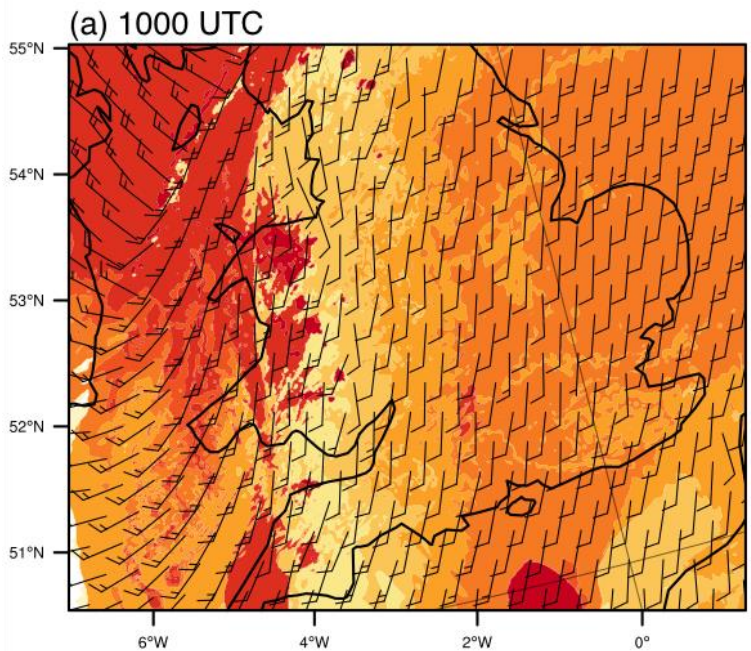

$6^{\circ} \mathrm{W}$ (b) 1400 UTC

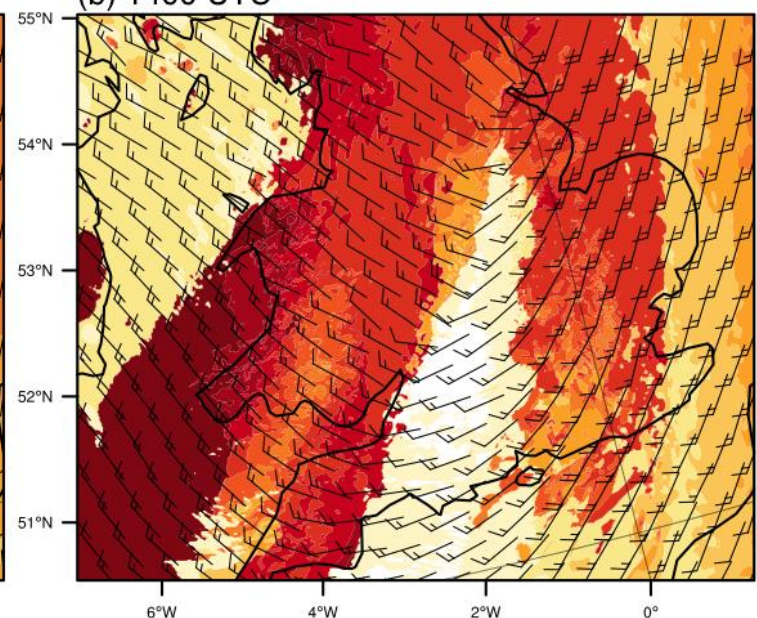

$200 \quad 600 \quad 1000 \quad 1400 \quad 1800 \quad 2200 \quad 2600 \quad 3000 \quad 3400 \quad 3800$ $\mathrm{LCL}(\mathrm{m})$

941 Figure 14. Simulation of lifting condensation level (LCL) (m, colored according to scale) and

942 surface winds (pennant, full barb, and half-barb denote $25,5,2.5 \mathrm{~m} \mathrm{~s}^{-1}$, respectively;

943 separation between displayed wind vectors is $30 \mathrm{~km}$ ) on the domain with 1-km horizontal grid

944 spacing at (a) 1000 UTC and (b) 1400 UTC 23 November 1981. 
(a) 1000 UTC

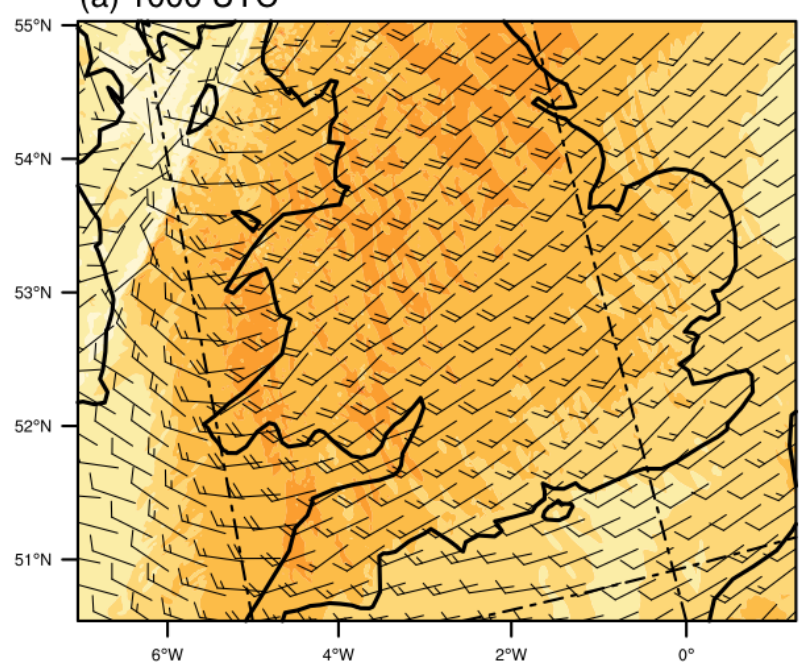

(b) 1400 UTC

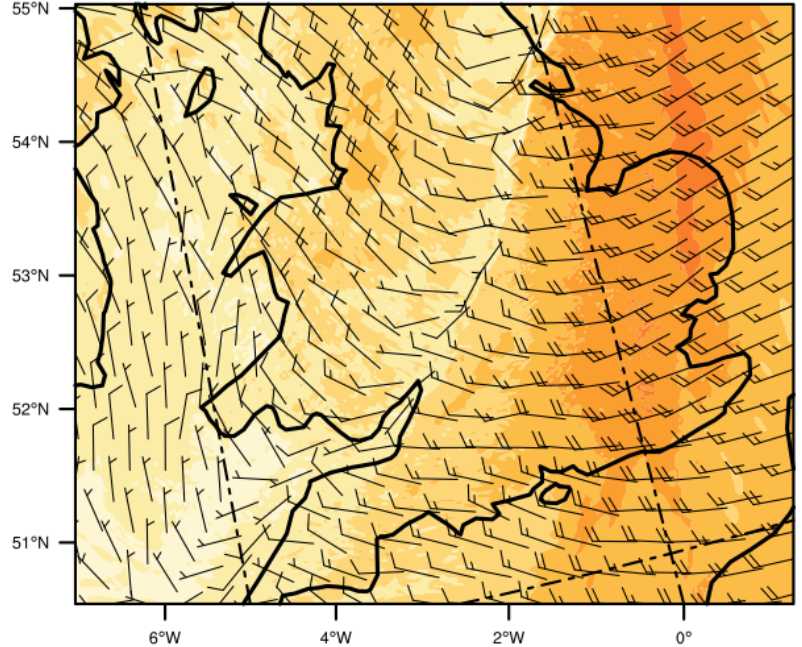

0-1 km Wind Shear $\left(\mathrm{m} \mathrm{s}^{-1}\right)$
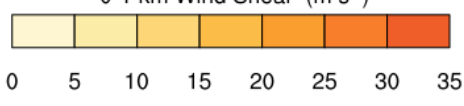

948 Figure 15. Simulation of $0-1-\mathrm{km}$ vertical shear of the horizontal wind in magnitude $\left(\mathrm{m} \mathrm{s}^{-1}\right.$,

949 colored according to scale) and direction (pennant, full barb, and half-barb denote 25, 5, 2.5 m

$950 \quad \mathrm{~s}^{-1}$, respectively; separation between displayed wind vectors is $30 \mathrm{~km}$ ) on the domain with 1-

951 km horizontal grid spacing at (a) 1000 UTC and (b) 1400 UTC 23 November 1981. 


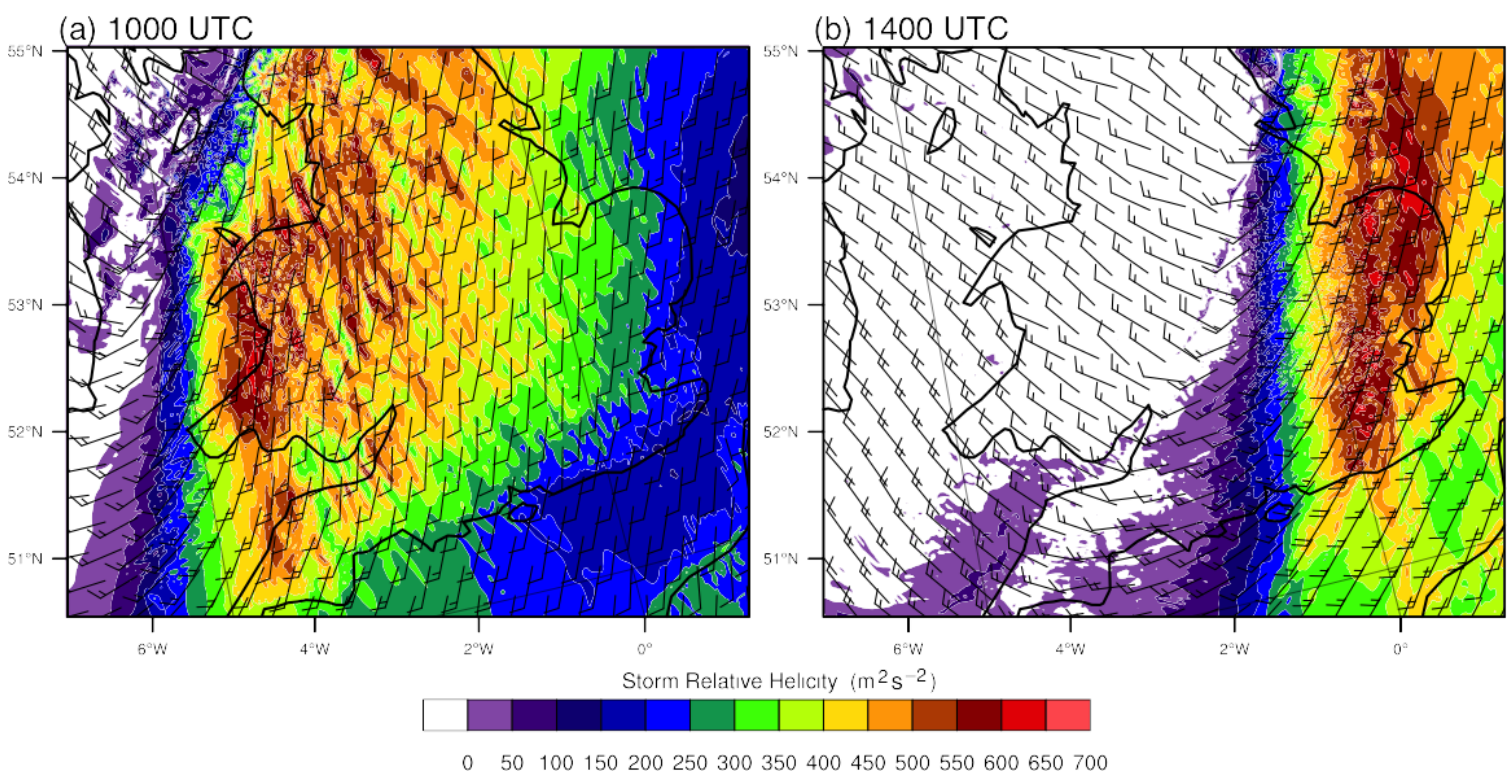

954 Figure 16. Simulation of $0-1-\mathrm{km}$ storm-relative helicity $\left(\mathrm{m}^{2} \mathrm{~s}^{-2}\right.$, colored according to scale) 955 and surface winds (pennant, full barb, and half-barb denote $25,5,2.5 \mathrm{~m} \mathrm{~s}^{-1}$, respectively; 956 separation between displayed wind vectors is $30 \mathrm{~km}$ ) on the domain with 1-km horizontal grid 957 spacing at (a) 1000 UTC and (b) 1400 UTC 23 November 1981. 


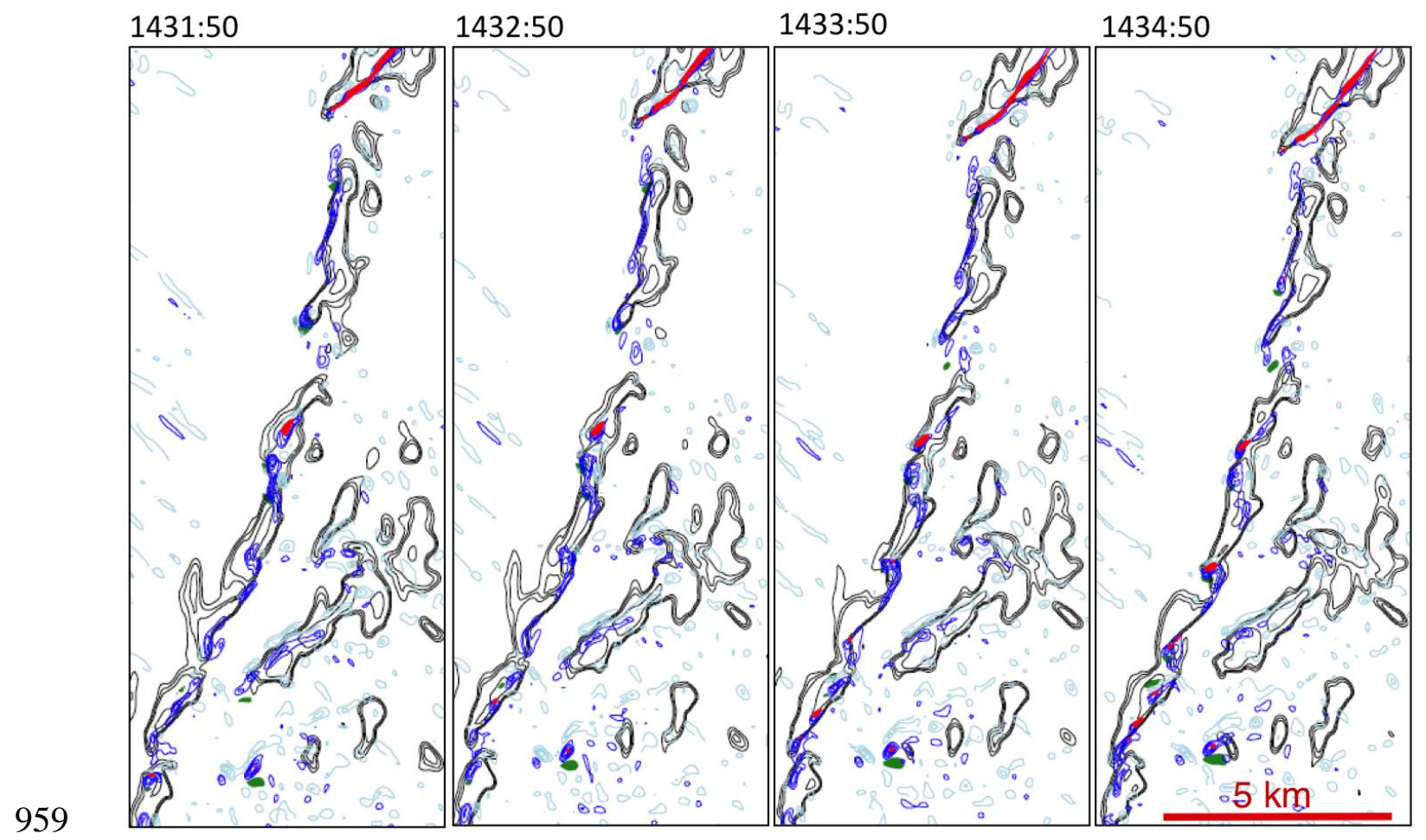

960 Figure 17. Simulation of radar reflectivity factor (black lines every $10 \mathrm{dBZ}$ ), absolute vorticity at

$961500 \mathrm{~m}$ ASL (positive values are contoured in dark blue solid lines every $0.005 \mathrm{~s}^{-1}$, starting from

$9620.01 \mathrm{~s}^{-1}$; negative values are contoured in light blue solid lines every $-0.005 \mathrm{~s}^{-1}$ every $0.005 \mathrm{~s}^{-1}$ ),

963 500-m updrafts (red fill above $5 \mathrm{~m} \mathrm{~s}^{-1}$ ), and 500-m downdrafts (green fill above $2 \mathrm{~m} \mathrm{~s}^{-1}$ ) from the 964 200-m horizontal grid spacing domain, plotted every minute from 1431:50 to 1434:50 UTC 23

965 November 1981.

966 

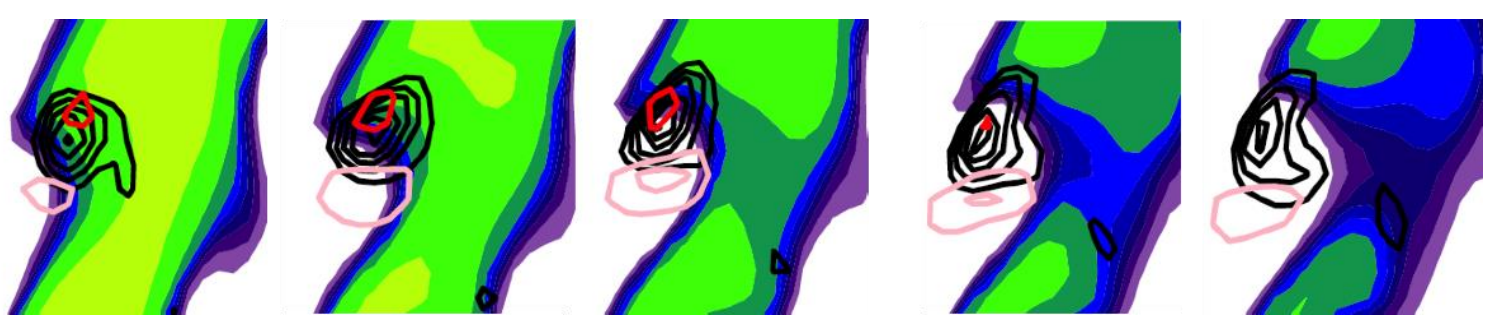

968 Figure 18. Characteristic structure and evolution of a simulated misovortex within the domain at 969 200-m horizontal grid spacing, plotted every $60 \mathrm{~s}$ around the time that it matures: radar 970 reflectivity factor (dBZ, colored according to scale in Fig. 16), absolute vorticity at $500 \mathrm{~m}$ ASL

971 (black contours every $0.005 \mathrm{~s}^{-1}$, starting from $0.01 \mathrm{~s}^{-1}$ ), 500-m updraft (red contours every $5 \mathrm{~m} \mathrm{~s}^{-}$

$972^{1}$ ), and 500-m downdraft (pink contours every $2 \mathrm{~m} \mathrm{~s}^{-1}$ ). Each panel is about $4 \mathrm{~km} \times 4 \mathrm{~km}$, and 973 the vortex is about $500 \mathrm{~m}$ across.

974 


\section{Locations of 90 Revised Tornado Reports}

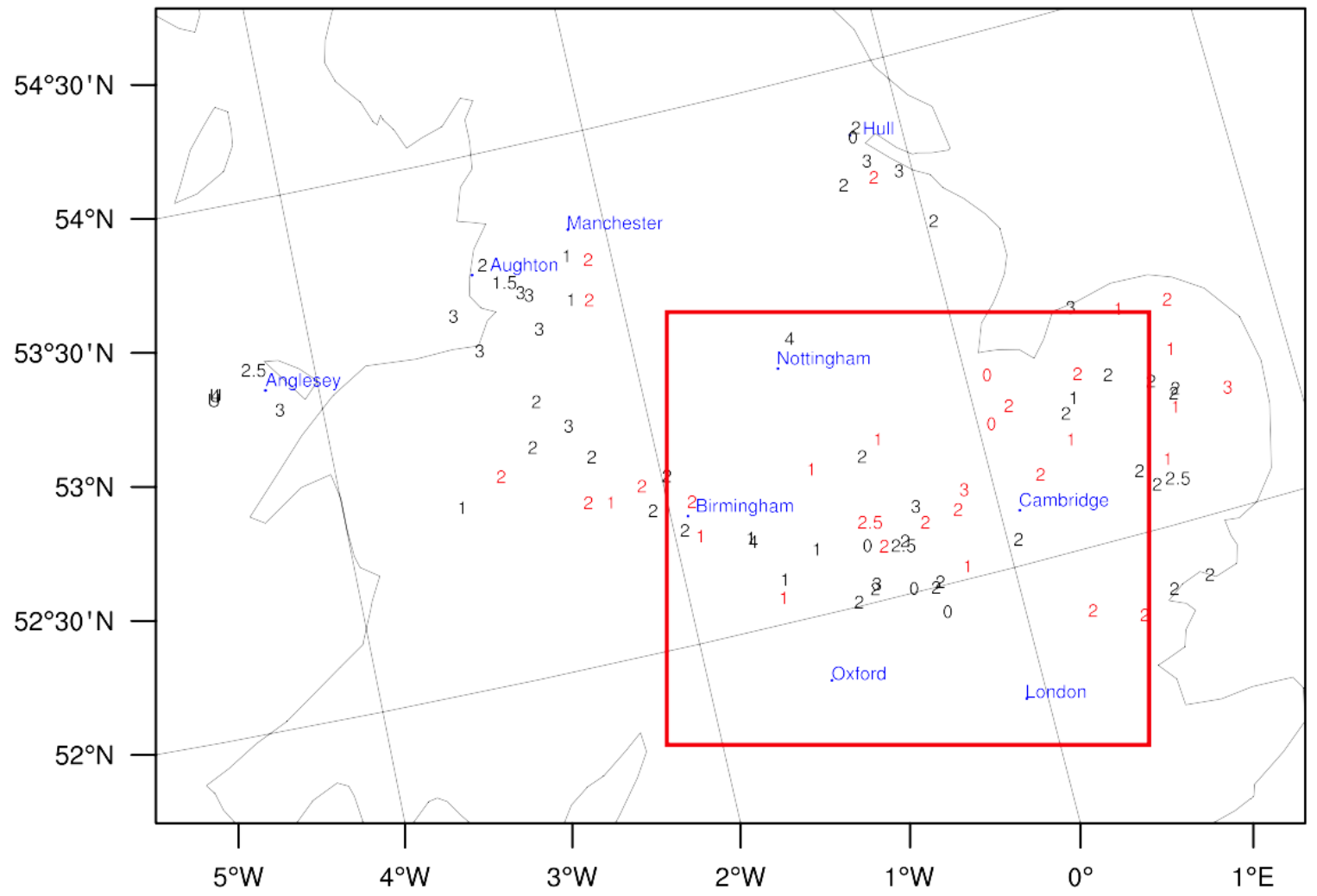

977 Figure 19. Locations of the 90 revised tornado reports from the TORRO database for 23

978 November 1981. Numbers represent their strength on the T scale. Reports verified by 979 TORRO (58) are classified as definite and plotted in black. Reports that have not been 980 verified (32) are classified as probable and are plotted in red. Locations discussed in the text 981 are labeled in blue. The red box indicates the location of the domain with 200-m horizontal 982 grid spacing. Locations of reports that appear to be located over water are a result of a coarse 983 representation of geography. 
a. Vorticity, $0.02 \mathrm{~s}^{-1}$

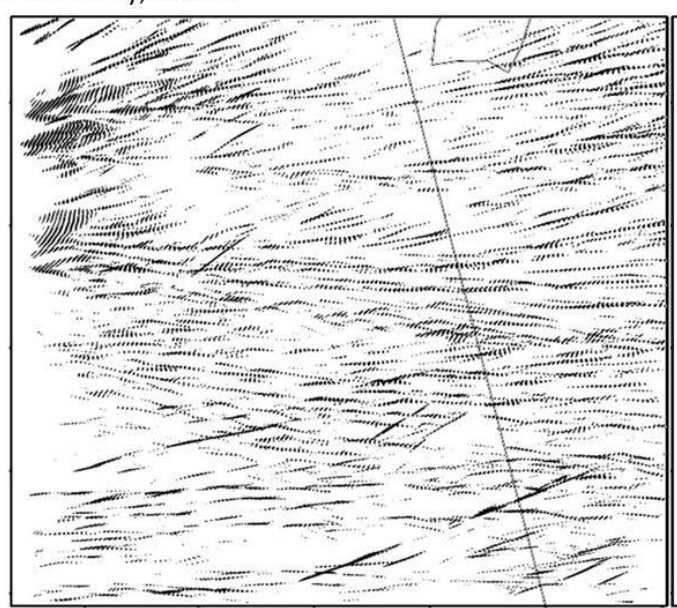

Vorticity, $0.025 \mathrm{~s}^{-1}$
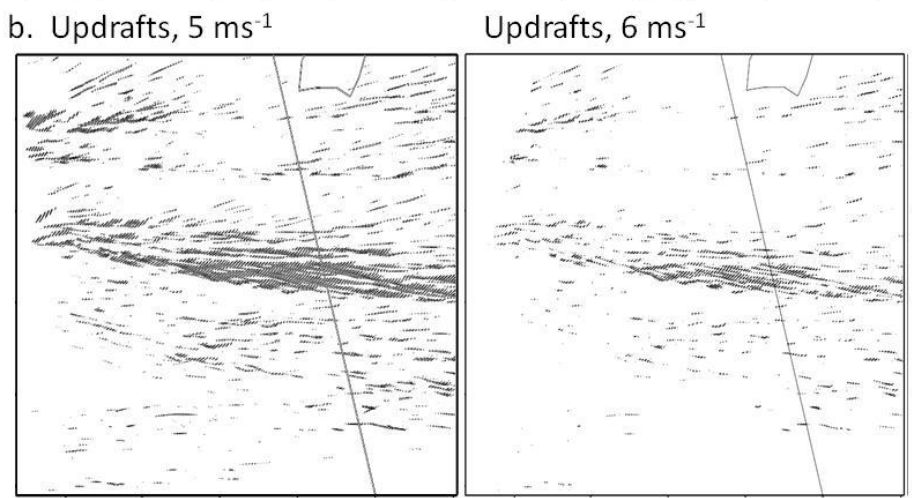

C. Downdrafts, $2 \mathrm{~ms}^{-1}$

Downdrafts, $3 \mathrm{~ms}^{-1}$
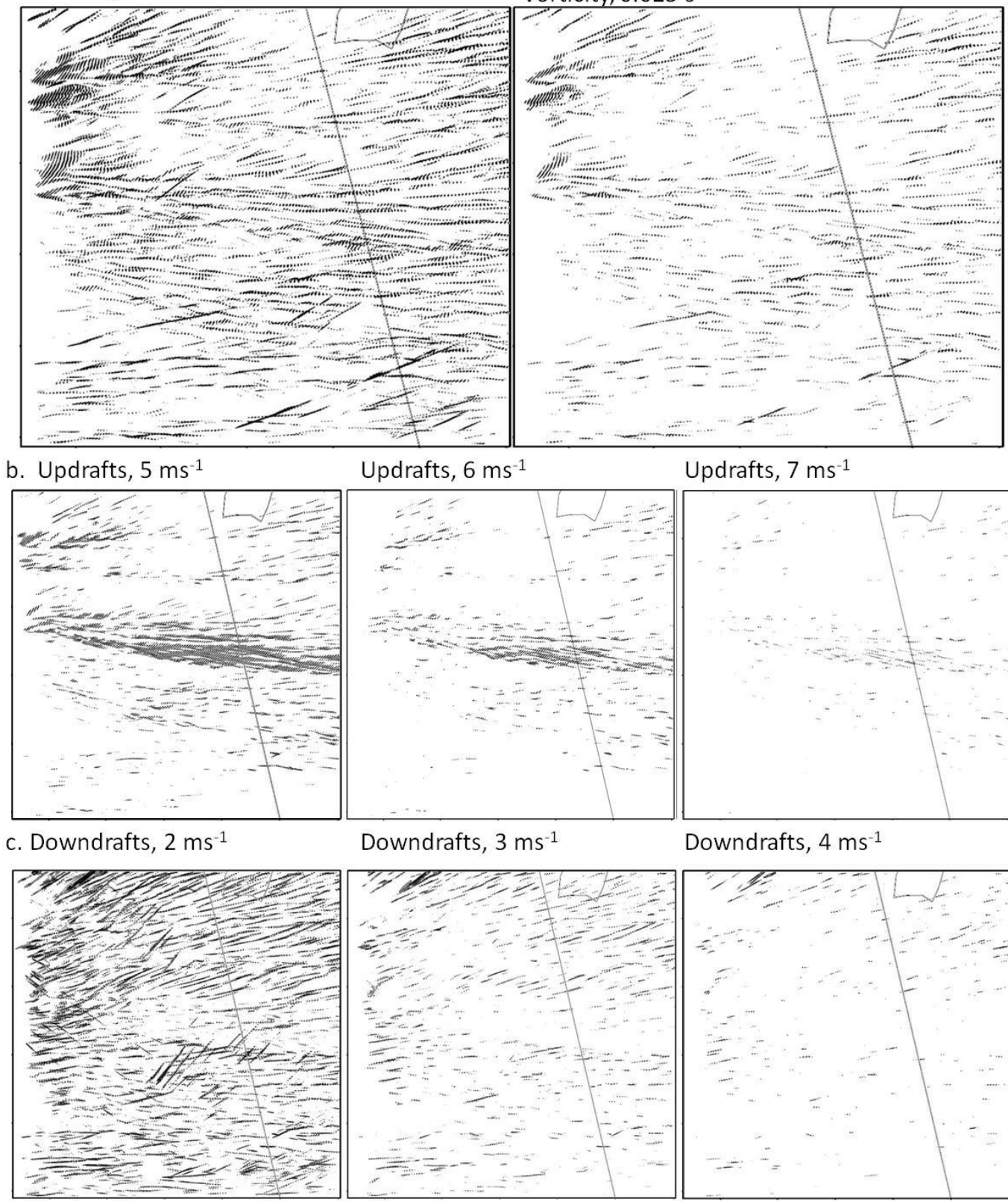

Updrafts, $7 \mathrm{~ms}^{-1}$

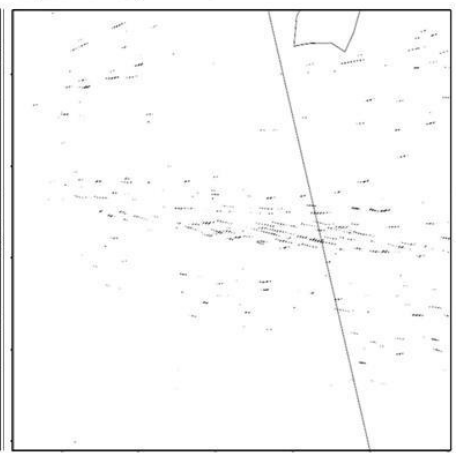

Downdrafts, $4 \mathrm{~ms}^{-1}$

Figure 20. Tracks of (a) 500-m absolute vorticity (0.02 and $0.025 \mathrm{~s}^{-1}$ ), (b) 500-m updrafts (5,

$988 \quad 6$, and $\left.7 \mathrm{~m} \mathrm{~s}^{-1}\right)$, and (c) 500-m downdrafts $\left(2,3\right.$, and $4 \mathrm{~m} \mathrm{~s}^{-1}$ ) plotted every minute from 1300

989 to 1600 UTC in the domain with 200 -m horizontal grid spacing. 


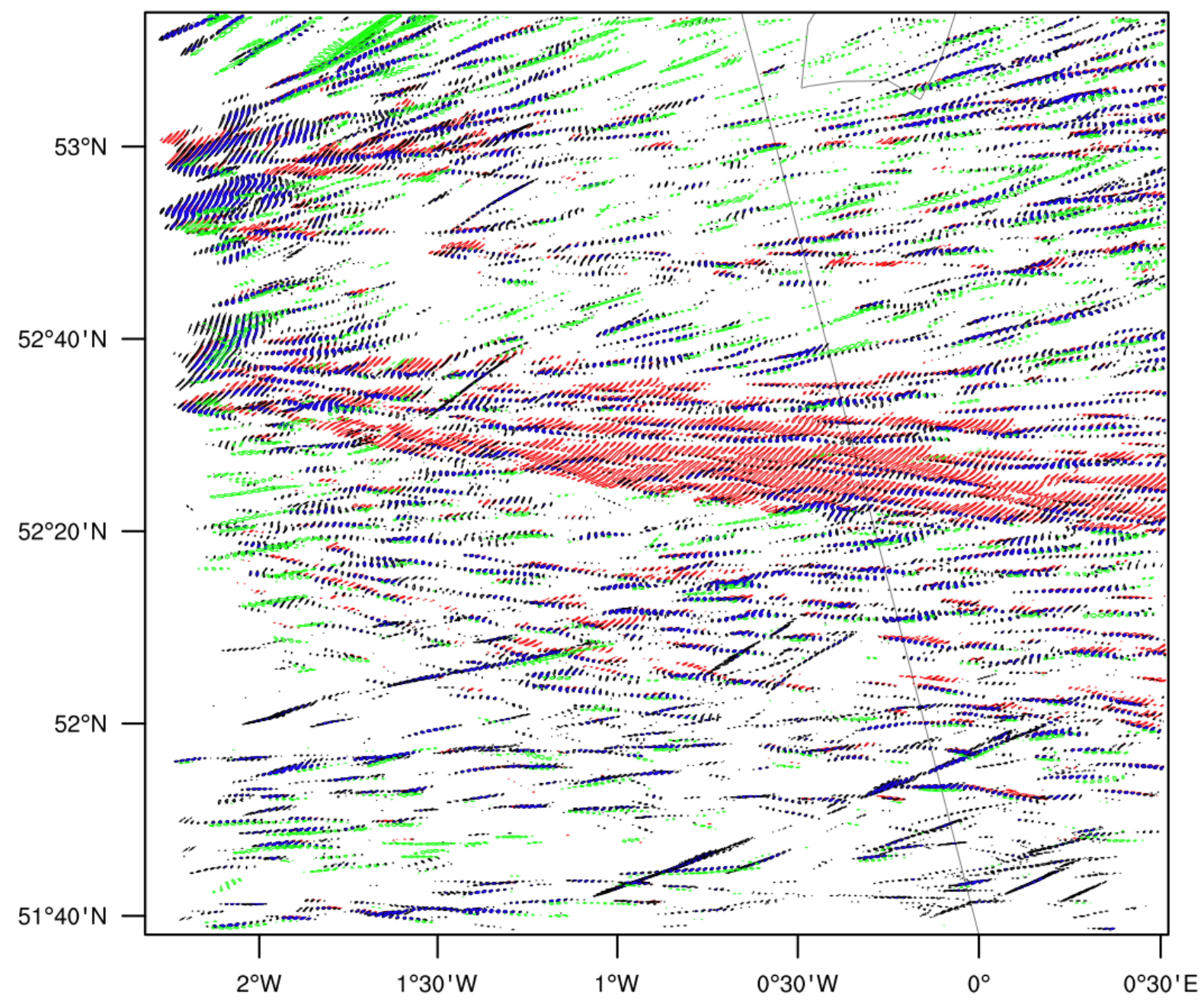

991

992 Figure 21. Simulation of $0.02 \mathrm{~s}^{-1}$ and $0.025 \mathrm{~s}^{-1}$ absolute vorticity at $500 \mathrm{~m}$ ASL (black

993 contours), $5 \mathrm{~m} \mathrm{~s}^{-1}$ updrafts at $500 \mathrm{~m}$ (red contours), and $3 \mathrm{~m} \mathrm{~s}^{-1}$ downdrafts at $500 \mathrm{~m}$ (green

994 contours) from 1300 to 1600 UTC on the domain with 200-m horizontal grid spacing. 


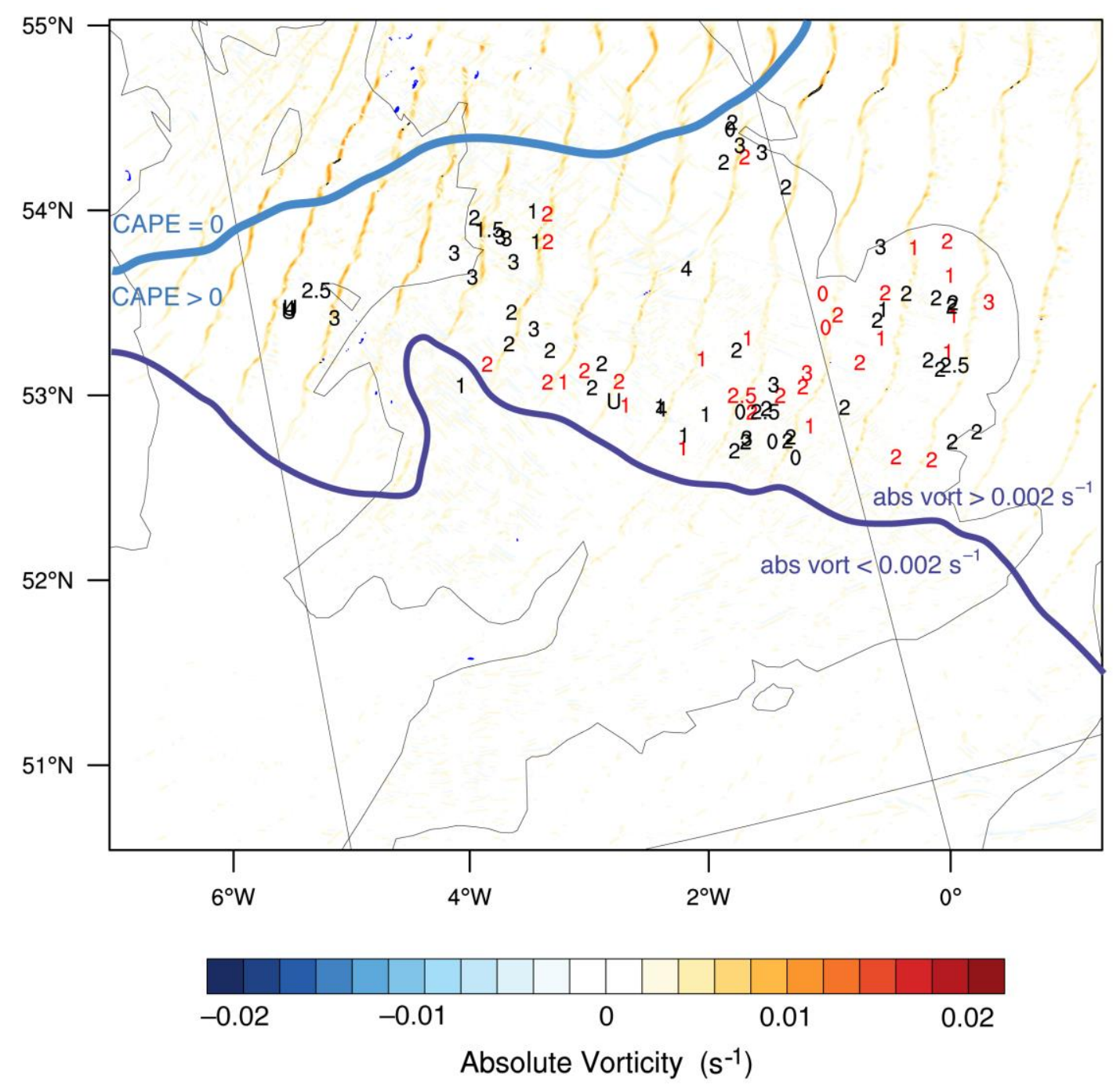

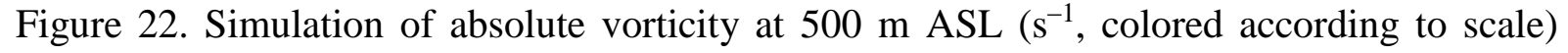
every $30 \mathrm{~min}$ from 0930 UTC to 1730 UTC on the domain with 1-km horizontal grid spacing.

999 Purple lines separate approximate areas with simulated absolute vorticity less than $0.002 \mathrm{~s}^{-1}$

1000 on the 1-km domain during the time of frontal passage. Blue lines separate approximate areas 1001 with simulated positive CAPE during the time of frontal passage. Locations of reports that 1002 appear to be located over water are a result of a coarse representation of geography. Locations 1003 of the 90 tornado reports from the TORRO database for 23 November 1981 . Numbers 1004 represent their strength on the T scale. Reports verified by TORRO (58) are classified as 1005 definite and plotted in black. Reports that have not been verified (32) are classified as 1006 probable and are plotted in red. 